University of Louisville

ThinkIR: The University of Louisville's Institutional Repository

Electronic Theses and Dissertations

$12-2004$

\title{
Corporate change and integration as a result of a merger : an analysis of organizational culture within a large full-service law
} firm.

Ilker Huseyin Onen

University of Louisville

Follow this and additional works at: https://ir.library.louisville.edu/etd

\section{Recommended Citation}

Onen, Ilker Huseyin, "Corporate change and integration as a result of a merger : an analysis of organizational culture within a large full-service law firm." (2004). Electronic Theses and Dissertations. Paper 1080.

https://doi.org/10.18297/etd/1080

This Master's Thesis is brought to you for free and open access by ThinkIR: The University of Louisville's Institutional Repository. It has been accepted for inclusion in Electronic Theses and Dissertations by an authorized administrator of ThinkIR: The University of Louisville's Institutional Repository. This title appears here courtesy of the author, who has retained all other copyrights. For more information, please contact thinkir@louisville.edu. 


\title{
CORPORATE CHANGE AND INTEGRATION AS A RESULT OF A MERGER: AN ANALYSIS OF ORGANIZATIONAL CULTURE WITHIN A LARGE FULL-SERVICE LAW FIRM
}

\author{
By \\ Ilker Huseyin Onen \\ B.A. Tiffin University, 1995
}

A Thesis Submitted to the Faculty of the Graduate School of the University of Louisville in Partial Fulfillment of the Requirements for the Degree of

Master of Arts

Department of Sociology University of Louisville Louisville, Kentucky

December 2004 
CORPORATE CHANGE AND INTEGRATION AS A RESULT OF A MERGER: AN ANALYSIS OF ORGANIZATIONAL C ULTURE WITHIN A LARGE FULL-SERVICE LAW FIRM

\title{
By
}

Ilker Huseyin Onen

B.A., Tiffin University, 1995

\author{
A Thesis Approved on
}

November 17, 2004

by the following Thesis Committee:

Thesis Director 


\title{
DEDICATION
}

This thesis is dedicated to my faithful and supportive parents

\author{
Mr. Orhan Onen
}

and

Mrs. Zubeyde Onen

who have provided me with the invaluable gift of education. 


\section{ACKNOWLEDGEMENTS}

I would like to thank my major professor, Dr. Cynthia Negrey, for her unwavering patience and insightful guidance during the entire process of this work. I would also like to thank my other committee members, Dr. Melissa Evans-Andris and Dr. Joy Hart, for their valuable input for the past two years. In addition, I would like to express my ultimate gratitude to my fiancée, Alicia Kozak, for her ever-present love and support during the most difficult moments of this project. Without her warm sentiment and soothing words, my efforts would have been even more strenuous. Also, many thanks are acknowledged to the Gillentine family in Hartville, Ohio for their kind support. I also owe my thanks to several good friends, Vasilios Antoniadis, Alexander Melikishvili, and Raman Vishwanathan, who through casual conversations provided me with countless instances of academic and personal advice. Finally, immense gratitude and respect are acknowledged to all the personnel in the chosen research setting. 


\begin{abstract}
CORPORATE CHANGE AND INTEGRATION AS A RESULT OF A MERGER: AN ANALYSIS OF ORGANIZATIONAL CULTURE WITHIN A LARGE FULL-SERVICE LAW FIRM
\end{abstract}

\title{
Ilker H. Onen
}

November 17, 2004

Previous research on organizational mergers has found that such a business activity bears an effect upon the structural and cultural foundations of organizations. Whether combining intellectual resources or capital, mergers combine workforces that have operated within very unique historical settings. This research focused on a merger between two law firms and the subsequent acquisition of an additional firm. Interviews with a random stratified sample of employees were conducted to gain insight on the cultural aspects of workforce integration. Throughout the research, culture and structure were used as interrelated aspects when addressing the merger. The main result of the research revealed how the employees of three different organizations accustomed to different cultural and structural legacies were affected by workforce integration. With the conclusion of the study, an additional research setting is offered to a growing area of academic interest. 


\section{TABLE OF CONTENTS}

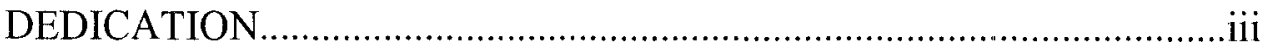

ACKNOWLEDGEMENTS................................................... iv

ABSTRACT

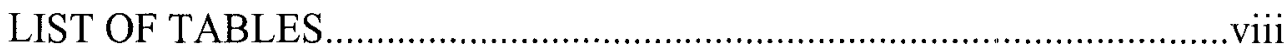

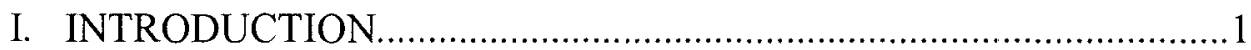

II. REVIEW OF THE LITERATURE ......................................................

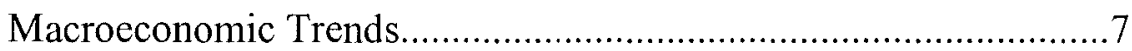

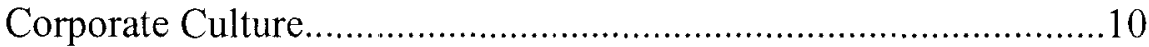

The Modern Law Firm.................................................................15

Previous Research in the Context of Current Research...................21

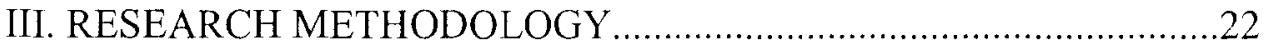

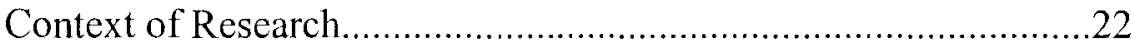

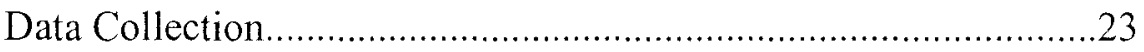

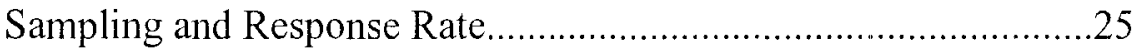

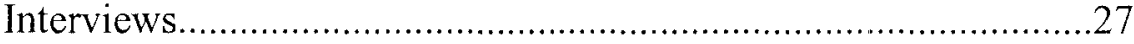

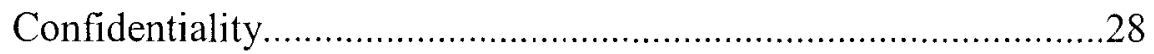

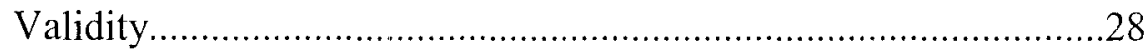

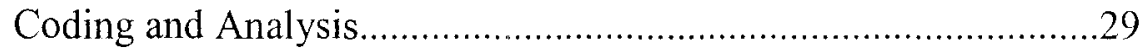

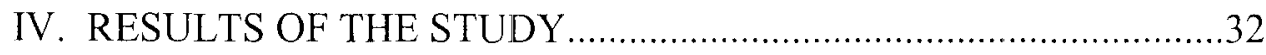

A Cultural Comparison of the Three Integrating Firms....................36 
The Integrated Law Firm: A-Z Law..............................53

Employee Impressions of A-Z Law's Policies and Practices.........70

Employee Impressions of the Merger............................76

Work Routine Change within the Integrated Workplace.............84

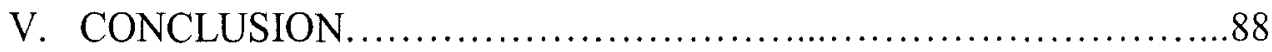

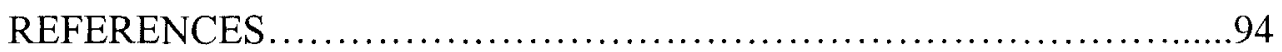

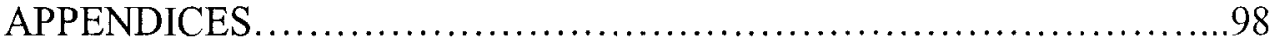

CURRICULUM VITAE ........................................... 112 


\section{LIST OF TABLES}

TABLE

PAGE

1. Research Objectives and Corresponding Analytic Themes and Sub-Themes...4

2. Chronology of Events Related to the Merger..................................................33

3. Employee Composition at the Time of Merger............................34 


\section{CHAPTER I}

\section{Introduction}

As a combined effort to gain productivity and vital resources and to increase efficiency, mergers are attractive for organizations seeking greater economic competiveness. This interest in the beneficial integration of capital, market share, and personnel has grown considerably since the beginning of the twentieth century (Browne and Rosengren 1987: 24). Many of today's companies are the result of past mergers. However, besides the orthodox measures of a merger's success or failure--mostly through the gauge of financial indicators--cultural considerations are becoming a greater factor in determining these outcomes (Marks 1999: 101). Much to the contrary of their initial prospects, many combined business endeavors fail due to a disregard of culture. Unfortunately, the full integration of employees accustomed to different work cultures may present a myriad of organizational disruptions. This possibility also holds true for merging law firms, the focus of this thesis, operating within the ever-internationalized, competitive market economy.

The ramifications of mergers within today's economy are even more profound when compared to previous eras of economic history. Globalization and the development of networked organizational affiliations in the production of goods and services have brought forth a new environment for mergers. The frequency and breadth of mergers have also expanded. The number of filings for mergers has 
tripled in the last decade while the "dollar value of commerce affected by these mergers has increased eleven-fold during the same period" (Federal Trade Commission, 2001: 2).

Modern law firms have adapted to these economic forces just as other large corporations. Because the need for providing legal services on a global scale has become more prevalent, law firms also seek to take advantage of the economic benefits of merging. Firm managers report law firm mergers are difficult to efficiently implement because of different cultures; the larger the firms, the more difficult the consolidation (Author Unknown 2000: 1).

The human aspect of mergers is quite evident. It is vital that we develop a deeper understanding of mergers and the impact they bear on the personnel of organizations. In 1985, with over 3,000 mergers enacted in the United States, tens of thousands of employees lost their jobs (Buono and Bowditch 1989: 5). A conservative estimate stated that 10 percent of the U.S. work force in 1990 was involved in a merger, an acquisition, or a related spin-off (1989: 6). Because mergers have become more voluminous and globalized, today's figures are likely to be higher. Mergers amount to tens of millions of workers being affected. In addition, many employees face job loss. Based on a recent estimate, approximately 500,000 U.S. employees can expect to become displaced from their employment as a result of these business activities (Probst 2003: 416). The largest companies in the United States, as indicated by Fortune Magazine's 500, reduced their total workforce from 14.1 million employees to 11.6 million from 1983 through 1993, 
although not all of this reduction is attributable to mergers and acquisitions (2003: 416).

Government agencies stressing the increased need for monitoring these transactions further confirms the prevalence of merger activity within the global market. For example, the Federal Trade Commission stated a need for additional resources to keep pace with merger activity (Federal Trade Commission, 1998). This fact merely discloses the scope of these transactions; it does not even hint of the difficulties encountered by researchers wishing to unearth the organizational culture of a particular firm. The modern law firm is just one categorical entity operating within the economy experiencing such organizational change.

The purpose of this study is to gain insight into corporate culture in the aftermath of an organizational merger. More specifically, the investigation of organizational culture within a newly merged American law firm is the goal of this research endeavor. Organizational change is paramount to the future development of the firm. Moreover, the rapid and widespread interaction of personnel is vital for the operation of any organization. Most interesting to this research is the fact that three different law firms merged and integrated their labor force into a single office. Such an aggregation, as the literature will abundantly demonstrate, can lead to a variety of contingencies. This research investigated the overall impression of work life expressed by employees facing the potential of social, procedural, and authoritative change within the new law firm.

Several research objectives were included in this research endeavor. First, the project presented an analysis of each firm's distinct culture. Identifying the 
cultural characteristics of the new firm was the second goal of the research.

Employee impressions of the new firm's policies and practices were another area of exploration covered in the research. The next research objective involved employee impressions of the merger based on different occupational positions within each respective law firm. Finally, the research also investigated how work routines changed as a direct result of the merger. The research objectives mentioned above framed the interpretation of the data. The table located below is an outline of themes relating to the research objectives.

Table 1

Research Objectives and Corresponding Analytic Themes and Sub-Themes

\begin{tabular}{|l|l|l|}
\hline Research Objective & Theme(s) & Sub-Theme(s) \\
\hline Pre-Merger Firm Culture & $\begin{array}{c}\text { Internal (Observations of } \\
\text { Own Pre-Merger } \\
\text { Culture) }\end{array}$ & $\begin{array}{l}\text { Firm Size } \\
\text { Billable Hours } \\
\text { Pro Bono Opportunities }\end{array}$ \\
& $\begin{array}{c}\text { External (Assumptions of } \\
\text { Other Firms' } \\
\text { Culture) }\end{array}$ & $\begin{array}{l}\text { Ritual } \\
\text { Daily Contact } \\
\text { Rumors }\end{array}$ \\
\hline
\end{tabular}




\begin{tabular}{|c|c|c|}
\hline $\begin{array}{l}\text { Post-Merger Firm } \\
\text { Culture }\end{array}$ & $\begin{array}{l}\text { Dominant Culture of XYZ } \\
\text { Law } \\
\text { Expectations } \\
\text { Normative Order } \\
\text { Bureaucracy } \\
\text { Hierarchy } \\
\text { Occupational Positions }\end{array}$ & $\begin{array}{l}\text { Little change from XYZ } \\
\text { Law employee } \\
\text { impressions } \\
\text { Competence } \\
\text { Salary } \\
\text { Benefits } \\
\text { Need for control } \\
\text { Efficiency } \\
\text { Bearing on creativity } \\
\text { Strength of recognition } \\
\text { Attorneys } \\
\text { Administrative Staff } \\
\text { Paralegals }\end{array}$ \\
\hline $\begin{array}{l}\text { Employee Impressions } \\
\text { of the New Firm's } \\
\text { Policies }\end{array}$ & $\begin{array}{l}\text { Administrative Issues } \\
\text { Rewards } \\
\text { Paralegals }\end{array}$ & $\begin{array}{l}\text { XYZ Influence } \\
\text { Technological conversion } \\
\text { Human resources } \\
\text { Consistency } \\
\text { Associate evaluations } \\
\text { Work flows }\end{array}$ \\
\hline $\begin{array}{l}\text { Employee Impressions } \\
\text { of the Merger }\end{array}$ & $\begin{array}{l}\text { Attorneys } \\
\text { Secretaries } \\
\text { Paralegals } \\
\text { Other Employees }\end{array}$ & $\begin{array}{l}\text { Optimism } \\
\text { Stability } \\
\text { Employee turnover } \\
\text { Increase in legal talent } \\
\text { Job insecurity } \\
\text { Benefits } \\
\text { Increased resources } \\
\text { Job security } \\
\text { Opportunity } \\
\text { XYZ influence } \\
\text { Human cost }\end{array}$ \\
\hline Work Routine Change & $\begin{array}{l}\text { New positions } \\
\text { Changes for personnel of } \\
\text { smaller firms }\end{array}$ & $\begin{array}{l}\text { Enlargement of office } \\
\text { Assimilation } \\
\text { Flexibility }\end{array}$ \\
\hline
\end{tabular}


The table on the previous page is an introductory map of analytic categories. Analytic themes emerged from the data and were framed in accordance to the research objectives. The detailed summary of results in Chapter 4 will demonstrate the association between the research objectives and themes that emerged from the data.

The following chapters consist of a literature review, research methodology, disclosure of results, and conclusion. The literature review, appearing as Chapter 2 in the thesis, contains three sections that address several aspects of mergers: macroeconomic trends, organizational culture, and the modern law firm. Chapter 3 describes the research methods used in the data collection. The research findings, discussed in Chapter 4, appear with five sub-sections that relate directly to each research objective. Major themes and sub-themes correspond to each research objective. The final chapter summarizes key findings and the implications of the research. 


\section{CHAPTER II}

\section{Review of the Literature}

The literature on mergers that is relevant to this research deals with three main areas: macroeconomic trends, corporate culture, and the development of the modern law firm. Each aspect of the literature review is divided into a separate section. These three areas of review are the reference point for the development of the research and are used throughout the scope of the data analysis. A fourth section relating to the limitations of previous research concludes the chapter.

\section{Macroeconomic Trends}

First, the recurrent theme within the macroeconomic aspect of mergers relates to the incidence of merger "waves". Previous to the merger wave of the late 1990s, four distinct merger waves are identified (Sterans and Allan 1996: 699). Specifically, the periods yielding such cyclical activity originated during the 1890s, 1920s, 1960s, and 1980s.

The first wave led to the development of monopolies, most notably in the areas of transportation (Ramu 1998: 16). These mergers of companies within the same industry, known as horizontal mergers, led to the domination of an entire industry by a few large organizations. The second wave created oligopolies such as the market composition of the automotive industry. These early merger waves were a result of an increase in economic concentration and a massive transformation from 
an agricultural to a manufacturing based economy (U.S. Senate 1998).

Conglomerate takeovers characterized the merger wave of the 1960 s as companies sought to diversify beyond their core activity (Ramu 1998: 17). During the 1980s, hostile takeovers were the dominant form of transaction as organizations sought to acquire cash for transferal to other areas of operation. The $1990 \mathrm{~s}$ presented a greater frequency of internationalized mergers. According to Federal Reserve Board Chairman Alan Greenspan, the latter three merger waves existed in a relatively unaltered economic structure (U.S. Senate 1998). As Chairman Greenspan noted:

The more recent merger waves, however, do not appear to have materially altered industry structure, perhaps owing, in large part, to the increased adaptability of our more mature and competitive industrialized economy.

The economy, as derived from the explanation above, is an adaptive form of an earlier economic structure. Furthermore, this orientation supplements the idea of post-industrialism; a theoretical paradigm that espouses the evolution of a core economic base of society that adapts to the new material needs of society.

Conversely, the unique set of characteristics inherent to the most recent merger wave occurring in the 1990 s contributes an area of contention within the literature when analyzing the characteristics of the base economic structure of this era and mergers occurring during past merger waves. With the advent of globalization and increases in the capabilities of information technology, new economic dynamism emerged. Indeed, mergers occurring among firms of different nations are now commonplace. Therefore, the breadth and complexity of mergers is even greater than previously conceived (Ramu 1998). 
Manuel Castells (2000) further elaborates on the notion of an altered industry structure and disagrees with Chairman Greenspan's evaluation of the most recent merger wave. Within his comprehensive work, The Rise of the Network Society, Castells argues the material base of the economy in today's world is fundamentally changed from the one presented by proponents of post-industrialism. Castells surmises the advent of a new epoch: The Information Age. In this economic era, "mega-mergers" are common (Castells 2000: 153). The average transaction size of these mergers "rose from $\$ 98.6$ million in 1991 to $\$ 421$ million in 1999" (Flom 2000: 757). The finance industry reinvented itself organizationally and technologically by consolidating into mega-groups capable of covering a wide range of financial services at a level never previously conceived. The global composition of world markets exists with a greater coalescence through these joint endeavors. However, the configuration of anti-trust laws, limited and only applicable to established national borders, became a key developmental element in the rise of these colossal financial organizations.

Anti-trust legislation and corporate tax code laws in determining the extent of merger activity are also widely discussed in the literature. Because merger waves reveal a cyclical nature, so do anti-trust regulations enacted by the polity (Hovenkamp 1994: 157). Alteration of tax codes can lead to more fertile ground for merging. Because efficiency is a core motivating aspect of mergers, tax codes providing companies with incentives may increase the opportunity to invest (Smirlock, Beatty, and Majd 1986: 3). 
Interorganizational imitation is the final macroeconomic aspect of mergers discussed within the literature (Sterans and Allan 1996: 703). Once mergers of significance take place by key corporations, other organizations follow. As this practice becomes more palpable, the result is the distinctive formation of merger waves.

\section{Corporate Culture}

A second area of literature regarding mergers encompasses corporate culture. Although the financial measures of a merger's success or failure are well established, the successful fusion of corporate cultures is a more elusive property to analyze. Each firm has its own set of values and operating philosophy (Mirvis 2001: 30). One effect that organizational change bears on corporate culture is exhibited by the employees of AT\&T. When AT\&T was broken apart, workers throughout the organization wore black arm bands to symbolize the death of a family member (Belasso 1990: 203). Although this example is vague and seemingly dramatic, further examples will demonstrate the impact mergers have on corporate culture.

A study concerning the merger between U.S. Air and Piedmont Aviation in 1987 is a revealing account of corporate culture. Originally conceived as a separate labor force, Piedmont was subjected to the standardized operational procedures of U.S. Air (Kole and Lehn 2000: 244). U.S. Air planned a "mirror-image" policy over the operating procedures of Piedmont. In effect, the policy led to a whitewash of the acquired units to relearn their jobs the U.S. Air way. A growing resentment developed among the employees of Piedmont during this organizational change. Already feeling a sense of fulfillment and pride with Piedmont, the employees of 
this firm began feeling that an inferior organization had acquired their firm and imposed deficient procedures. The contemptuous impulses inevitably spread as inhibitors of productivity. The authors contend that the merger, both through financial and cultural considerations, failed due to a lack of recognition regarding the importance of organizational culture.

Within the same area of literature, the comparison of firm size and the relative cohesion or disruption that occurs once a merger has taken place are investigated. During mergers, an acquiring firm may impose its culture upon a smaller, acquired entity (Nahavandi and Malekzadeh 1988: 81). Resistance to the obligatory standards is common in such a case. Acculturation is a key concept in these authors' thesis. Four modes of acculturation are identified: integration, assimilation, separation, and deculturation (1988: 82-3). Integration results in maintaining the autonomy of the acquired firm as it cooperates with the acquiring party. Assimilation relates to the complete acceptance of the acquiring firm's culture. Separation, similar to integration, involves little interaction between merged parties and a minimum degree of cultural exchange. Finally, deculturation occurs when members of a firm denounce the acquiring firm's culture outright. Although these four modes of acculturation are useful in determining the relative cohesion or conflict between corporate cultures, a given culture should never be regarded as "right or "wrong" (Schultz 1995: 12). As the authors contend, cultural integration occurs with outcomes ranging from shared viewpoints, disagreements with other viewpoints, and indifference to others. 
Another area of corporate culture relates to a phenomenon known as a culture of inferiority. This perception occurs when companies hire externally for new employment (Kanter 1984: 93). As a result, a widespread implication emerges whereby employees tend to believe that the company views existing employees as unqualified. This view leads to the creation of a culture that values outsiders as a source of innovation (1984: 94). Employees feel capable when managers find internal talent to fulfill the company's needs (1984: 151). A corporate culture that seeks internal promotion, as the author contends in her analysis, can produce the value of membership among employees.

Adding to the inherent complexity of organizational culture, one author presents another dimension of the topic: the possibility of subcultures. Subcultures stem from many differentiated positions with varying degrees of authority (Fine 1984: 239). Even within a single firm, a variety of subcultures may exist due to work conditions. The unique condition of labor also provides reinforcement to this notion. Another author adds that subcultures develop based on differences in professional backgrounds, functional position in the organization, and affiliation to different business areas (Schultz 1995: 12). These subcultures are not to be viewed as "right" or "wrong", but by the rationale that some organizational units agree, disagree, or are indifferent to various aspects of the dominant culture. The harmonious interaction of subcultures is important to the cohesion of an organization; the profound change occurring from a merger may expedite an intensification of organizational intricacies. 
One such example of the existence of subcultures involves Xerox. As the company grew, officials decided to move the research and development component away from manufacturing. Company officers wanted to shelter this business unit from the daily demands of manufacturing, thus creating a spatial division of labor (Schoenberger 1997: 187). Because a direct collaboration on the product line was not necessary, the transfer of information was vital to maintaining contact with the two separate divisions. However, the Palo Alto Research Center (PARC) became removed from the Xerox environment, which led to the development of a specialized research center that was "very unlike Xerox" (1997: 188). The research center also hired outside employees and rarely promoted existing Xerox employees. No institutional connection existed between Xerox proper and PARC, other than technological integration. Ideas were not exchanged as they occurred, but only after the final product neared completion. Management could not guide development of products based on their market strategy. In addition, the divergence of culture came to the point of tension as core management described PARC employees as "wayward" and "undisciplined" (1997: 188).

Industry relatedness is another area of consideration in the analysis of corporate culture and mergers. During a merger between Fujitsu and ICL Systems, rivalry seemed indirect due to each company having market share in subtly different areas of the information technology industry. Although related in industry--in this case, information technology--both firms retained a great degree of sovereignty (Author Unknown 1993: 67). Other American firms, as earlier acquisitions of Fujitsu, experienced operational sovereignty. The uniqueness of the technology 
industry may also prove a great determinant in the success of these types of mergers. Cooperation in technological conceptualization and the allocation of vital combined resources can yield a greater potential for innovative output. However, the interaction of people is a guiding principle in the maintenance of a "successful" merger (Smith 2000: 2).

Legitimacy and worker consent are two related concepts helpful in understanding corporate culture and providing sufficient background for the proposed research. Within this work, Hodson (1999) states that the effective use of power rests upon an adherence to an agreed normative order. Differences in power between workers and management influence the pattern of normative order (1999: 295). The author provides two illustrative examples in support of his thesis. In Germany, unions are strong and the normative arrangement includes reduced hours of work and more vacation. Conversely, in Japan unions tend to hold less power, open-ended work arrangements, excessive hours, and expectations of effort are the norm. However, norms for management are to cease abusive practices (1999: 296). Trust and legitimacy, according to the author, are formed when the norms of fringe benefits, compensation, promotions, vacation time, training, and job security occur.

Finally, the remaining area of emphasis in the literature regarding corporate culture addresses how organizational communication impacted employees before a merger. In the research, communication was found to be a variable that reduces uncertainty among employees (Schweiger and Denisi 1991: 111). Two plants operated by a Fortune 500 company in a light manufacturing industry were the research settings for this study. Quantitative data collection was used to test three 
hypotheses. The first inferred that a general announcement of a merger would lead to lesser degrees of employee uncertainty. The second stated that an official meeting (merger preview) would lead to lower levels of uncertainty. The final hypothesis tested the stabilizing impact of a merger preview over time. Results from surveys given at various times proved supportive of all three hypotheses. Therefore, uncertainty waned once communication addressing the merger was disseminated.

\section{The Modern Law Firm}

The final area of literature encompasses the specific historical development and characteristics of the modern American law firm. Knowing the inherent characteristics of this enterprise undeniably facilitates the proposed research. Law firms participate in consolidation for the same economic purposes as other businesses. The transformation of the law firm in the United States increasingly became highly competitive, openly commercial, and profit-orientated (Katzman, Galanter, and Palay 1995: 30).

The structural enlargement of the law firm came into existence at the turn of the twentieth century (Galanter and Palay 1991: 2). At first, these larger law firms became subject to ridicule and were referred to as "legal factories" (1991: 18-9). Furthermore, client imitation was prevalent during this era because expansive growth occurred in the manufacturing base of the economy. In other words, law firms took on the organizational structure of their clients (corporations) as they grew and required a more centralized structure of governance during this surge of economic expansion. 
Early in the $20^{\text {th }}$ century, the most notable characteristic of the large law firm came to the fore. A structural archetype known as the "Cravath System" became the dominant organizational model for law firms to the present. During this era, corporate clients' legal needs evolved, as legal representation demanded more repetitive and high quality work (Fergus 2000: 1). Within this organizational schema, a two-tier hierarchy was introduced, with partners and associates comprising these two components. Basically, this system became focused on a pattern of work interaction similar to a mentor/apprentice model. Partners, as the more seasoned lawyers in the law firm, retained clients and offered legal work for associates. Through a lengthy process, usually lasting six to twelve years, associates could enter the realm of partnership only after a careful evaluation process. Within this hierarchy, partners exercise ownership of the business through allocating profits and providing operational direction, while associates serve as employees of the firm. Although a distinctive hierarchy among partners and associates exists, the relationship between all attorneys is characteristically "collegial" (Lazega: 2001). Within the collegial organization of law firms, attorneys are perceived as equals in relation to education and training. Therefore, attorneys utilize the knowledge of their colleagues specializing in different areas of law to produce legal work product for the law firm.

The Cravath System also offers a profitability mechanism unique to the law firm. Traditionally, law firms realized profit through the concept of "leverage". Such an arrangement requires a large group of associates who receive a salary "equal to only a fraction of the revenues they generate, with a lion's share divided 
among partners" (Samuelson \& Jaffe 1990: 190). The compensatory and prestigious appeal of partnership allows associates an opportunity to advance within the law firm only after stalwart service is achieved. However, the loss of an associate to partnership can lead to a decreased chance of profit. The premise of the Cravath System is to hire proportionally more associates to maintain favorable leverage.

Before 1960, large law firms were recognized for their specific location, especially the more notable big city law firms in New York, Washington D.C., and Chicago (Katzman, Galanter, and Palay 1995: 28). The large law firm characteristics changed as regional multi-city law firms emerged. An industry shift toward large practices became the dominant form in the legal services industry. The growing economy along with the increased inclusion of women in the labor force, internationalization of business, and innovations in information technology all contributed to the growth of the modern law firm (Galanter and Palay 1991: 38).

The structural development of the large law firm provides several departures from the earlier model. Branching and corporate practice are the signature characteristics of today's large law firm. Corporate practice itself became a business that included a large staff, high overhead, and intense specialization (1991:17). Furthermore, the lay population of the law firm increased dramatically (Hoffman 1982: 336). An industry shift away from services in the public domain to a wider practice of the bar became evident. This trend tended to draw the most promising and qualified attorneys to the domain of corporate practice. 
The evolution of the modern law firm has brought forth a more businessorientated approach to producing legal services. At the fore of this process is the evolving concept of professionalism within the legal field. Profession is a concept originating in the Middle Ages, which included a "sense of calling, purpose, and creed to uphold values under God" (Kelly 1994: 14). This concept, often times contentiously debated, has several meanings in law. Some include an adherence to expertise, effectiveness, doing things well, engaging in appropriate behavior, and maintaining good appearance. Professional development is attained through the process of engaging in legal work. Large law firms benefit practicing attorneys by providing the most sophisticated development in an environment where major clients pose legal problems of great complexity (1994: 10). Smaller law firms present accelerated professional growth within a setting free of bureaucracy and containing a small group of colleagues. Although few studies exist in the realm of professionalism within the legal field, one in particular examines the issue in detail. In an investigation of legal professionalism, Sandefur (2001) uses two theoretical paradigms in her approach: the Professional Purity Thesis and Client Type Thesis. The Professional Purity Thesis is centered on a core of strong professional values that remained free of non-legal considerations. The Client Type Thesis surmises that professionalism is greatly influenced by the clients represented (2001: 382). The author contends lawyers' independence exists like that of doctors in that they practice immediately from their training. Clients seek doctors and lawyers at their own will. However, attorneys have increased economic dependence on certain types of clients. "Prestige legitimates authority in situations in which the 
role or activity that accords such prestige is deemed relevant by interactants" (Sandefur: 2001: 384). On a wider scale, clients with greater economic power confer a higher prestige on attorneys representing them. Therefore, core economic values are represented rather than core professional values of the legal profession.

The study was carried out through a survey provided to hundreds of Chicago lawyers in 1995. Practicing attorneys from forty-two areas of practice were represented in the study. Respondents were randomly chosen from a sample of attorneys in good standing with state and local legal authorities. Attorneys were asked about the amount of time spent in certain practice areas. A scale of one to five (1 to 5) was offered as a measurement of prestige, whereby respondents would rate his or her own activities along with an array of legal activities outside his or her particular area of practice. They also were asked to assign scores to a long list of legal specializations. At the high end of this model were legal specializations such as probate, tax, and employment/labor law. On the opposite end of the prestige spectrum were juvenile, immigration, and divorce law. Several hypotheses, formulated to relate to the theoretical frameworks were investigated.

According to the data, many hypotheses supporting each theory became evident. The Client-Type Thesis revealed the following associations, all of which were statistically significant: greater business generated led to a higher prestige score; the lower social status of an individual client yielded lower prestige scores; and finally, an increased intellectual challenge of the field of law revealed a higher prestige score (Sandefur 2001: 388). The Professional Purity Thesis also was supported by the data through several hypotheses: a greater aggregate of legal skill 
and knowledge required in a field of law corresponded to a higher prestige score;

the more frequently a field of law required an attorney to appear in trial related negatively to a lower prestige score; and a higher frequency of appellate court appearances positively affected prestige score (Sandefur 2001: 389).

Legal professionalism is relevant to law firm mergers in the context of corporate culture especially when regarding the differences between the clientele of large and small law firms. Although the American Bar Association enforces a body of values for attorney conduct, the concept of professionalism has subtle variations when types of clients are concerned. Some argue that the definition of legal professionalism as outlined by the American Bar Association is a broadly acceptable mode of conduct within the legal profession (Ravenel 2002: 33).

The author continues the discourse by identifying several areas that affect professionalism within law firms: "mentoring, pro bono work, continuing legal education, and discipline" (2002: 35). As the author contends, professionalism is nurtured and further developed within the confines of a practice setting. Therefore, the concept of legal professionalism possesses slight variations based upon the reinforcement provided by colleagues within law firms. Within the area of law firm mergers, lawyers from merging firms may find variance in professionalism, which in turn may influence the way these lawyers regard the other law firms. Attitudes on professionalism may diverge due to dissimilar practice areas. Although legal professionalism is explicitly defined by the American Bar Association as well as state and local bar associations, law firms provide the work environment for expanding these broad tenets of professional conduct. 


\section{Previous Research in the Context of Current Research}

The three main areas of the literature review encompass macroeconomic trends, corporate culture, and the modern law firm. The main limitation of this review consists of a lack of research conducted on law firm mergers. The literature facilitates an understanding of the economic dynamics of mergers, the characteristics of corporate culture, and the development of the modern law firm. However, very few research studies directly address law firm mergers. The aim of this research is to investigate a law firm merger between three separate law firms.

The research has several objectives. The first objective is a comparative analysis of each firm's pre-merger culture. Second, the research identifies the new firm's cultural characteristics. Third, employee impressions of the new firm's policies and practices is addressed. The next research objective relates to employee impressions of the merger based on different occupational positions. The final research objective investigates how work routines change as a direct result of the merger. 


\section{CHAPTER III}

\section{Research Methodology}

This research examined the organizational culture of a merged law firm consisting of three previously autonomous firms. It had several objectives. First, the project offered a comparative analysis of each firm's distinct culture prior to the merger. Identifying the cultural characteristics of the new firm was the second goal of the research. Employee impressions of the new firm's policies and practices are another area explored in the research. The next research objective involved employee impressions of the merger based on different occupational positions within each respective law firm. Finally, the research also investigated how work routines changed as a direct result of the merger.

\section{Context of Research}

A merger announcement took place that officially combined the law offices of $A B C$ Law and XYZ Law into a new organization, A-Z Law. Each law firm possessed offices in several cities and complemented one another in areas of legal expertise. The city of Stonebridge was the only site where workforce integration occurred. Shortly after the announcement, an acquisition of a small specialty law firm, EquiLaw, took place. Due to lease obligations, the combined firm operated in two different work sites. The personnel of $\mathrm{ABC}$ Law and EquiLaw integrated in an office away from XYZ Law. This arrangement lasted for nearly two years until 
they were brought into the work environment of XYZ Law. Therefore, full office integration occurred two years after the merger announcement.

The motivation for these organizations to consolidate into a single larger organization is supported by the literature. Adaptation to the pressures of competition is the main reason for such a transaction. The development of the modern law firm into a profit-orientated business creates a similar economic need to increase competitiveness. Specifically, the combined legal resources derived from a law firm merger create a wider area of practice and expand the amount of legal knowledge within a firm. This combination leads to a greater likelihood of maintaining and expanding a firm's client base. As a combination of three law firms, A-Z Law sought to enhance its competitive position both within its region and on a national level. With competitors engaging in similar practices, A-Z Law grew to meet the future challenges of legal practice.

\section{Data Collection}

The research used qualitative long interviews to gain insight into the subjective experiences of employees within the merged law firm. Three years had passed since the official announcement of the merger to the commencement of the interviews. However, full workforce integration took place two years after the announcement of the merger. This was attributable to lease obligations by some of the merging parties.

Grounded theory was the guiding perspective behind the chosen methodology. In this approach, theory emerged from the findings directly, as opposed to initiating theory first and then subsequently testing theory through the 
results of research (Merriam 2002: 142). The construction of theory was directly dictated from the standpoint of those living through experience. This method of data collection allows for analysis and theory to exist in a close relationship to one another (Straus and Corbin 1998: 12). Because the field dictates the findings, preconceived relations among different variables were not hypothesized (Babbie 1999: 261). Moreover, by utilizing a single research setting, qualitative interviewing was most useful in attaining the insight of each employee's subjective experience (1999: 269). In addition, the total number of potential participants within the firm was greatly below the minimal sampling requirements of quantitative research methodology.

Qualitative interviewing was used to generate a deeper view of each participant's life within the law firm (Berg 2000: 81). During interviews, each employee had the opportunity to explain in detail various aspects of employment. Interview questions were formulated in a manner consistent with established literature, and accordingly, reflect the generalizations of previous investigations and not solely on premature observations. The use of an open-ended research tool increased the potential for a detailed description of organizational culture and the organizational cultures of their previous firms.

The types of issues covered by the questions (see Appendix A) are rooted in the literature. Questions addressing knowledge of any formal pre-merger communications, meetings, or other activities are vital to the understanding of this merger. In addition, general questions tapped occupational tasks and employees' impressions of their work conditions. Procedural change is another topic covered in 
the literature that was investigated in my interviews. Other questions regarding the specific before and after impressions of the merger from the employees' perspective provided a baseline for cultural comparison among the three independent organizations involved in the merger.

Besides using a standardized format of questions to investigate employee impressions of the merger, work-specific questions were posed to gather a greater understanding of each respective position within the firm. Attorney-specific questions addressed the standards of billable hours, pro bono work opportunities, and impressions of paralegals and the support staff. Paralegal-specific questions were similarly structured due to the existence of billable hours. Paralegals were asked to disclose their impressions of attorneys and the support staff. Secretaries and other employees received questions regarding extra work and the effects of extra work on their lives outside the law firm. In addition, these employees were asked to give their impressions of attorneys and paralegals.

\section{Sampling and Response Rate}

Approximately fourteen long interviews (please refer to Appendix B) of employees at various levels of employment in the firm were conducted. The primary criterion for the selection of a sample was the presence of an employee during the time of the merger. A widespread integration of three offices in addition to normal turnover had led to employee mobility from this new firm. Those employees remaining at the firm are the population from which the random sample was drawn, stratified by four broad occupational groupings (attorney, paralegal, secretary, and other employees), to provide a broad array of viewpoints from 
different positions relative to authority, contact with clients, and work arrangements. A certain degree of sampling bias exists from the standpoint that employees selected from the law firm population are those employees who decided to remain at the law firm. Excluded from the study are those employees who left the law firm. However, by ensuring a maximum range of possibilities in the sample selection process, the biases were minimized.

The sample fell three participants short of the proposed sample of seventeen, with the shortage attributable primarily to the "partner" occupational category. All other occupational categories met the sampling requirements within the proposed methodology. The overall response rate for the research was 33\%. However, over one-half $(53 \%)$ of the total number of letters were sent to partners. A more accurate picture of the total response rate is revealed when comparing the response rate of partners $(9 \%)$ to the combined response rate of the remaining occupational categories $(60 \%)$.

The most obvious reason for the lower response rate of the partners was a lack of time associated with demanding work schedules. Although the research setting was within a dynamic workplace whose employees are performing tasks throughout the day, partners of law firms fulfill many influential departmental positions within the firm. As the highest occupational position within the two-tier Cravath System, partners also possess more decision-making authority, higher billable rates, and increased requirements for travel. Therefore, the demands set forth by this occupational position made it less likely to receive a prompt response. To compensate for non-responses, follow-up letters were sent after a three week 
period. After another three week period elapsed, the non-responses were formally deemed a refusal to participate in the study. A vast majority of the invitation letters sent to partners reached this outcome.

\section{Interviews}

The interviews were conducted at a place deemed comfortable by the participant. After the initiation of a pilot interview at the firm, the researcher acknowledges that visibility of the research endeavor was a sensitive issue, even after contemplating the most far removed and decentralized location for the interview. Anonymity was an obvious issue when negotiating a location for the interview. Participants received an invitation letter via regular mail to their homes that denoted the researcher's contact number. In all cases, the participants and the researcher negotiated a time and setting after normal work hours. Most interviews took place in café/restaurant-type locations promptly after work, while some were conducted at the homes of participants on the weekend. Each setting was relatively free of disruptive noise as well as being situated away from other co-workers.

The primary stipulation for the selection of a location from the researcher's standpoint was to discover a setting more removed from the direct proximity of the office; this factor in effect excluded the downtown area due to the foreseeable chance of encountering other employees. Interviews were tape recorded after gaining the explicit consent of each participant. Interviews ranged from thirty minutes to one and one-half hours with an average of forty-five minutes. 


\section{Confidentiality}

Confidentiality was closely monitored throughout the research. Such a regard to confidentiality was achieved through the concealment of the specific characteristics of name and the location of the researched organization through the use of fictitious terms. In addition, the names of the participants were altered for anonymity during the writing phase of the thesis. During the course of data collection, each individual participant received a case number. These records were secured at the home of the researcher. Furthermore, as with all proposed research that fulfill the guidelines of the university's internal review board, informed consent forms were provided before each interview took place (please refer to Appendix C).

Employees participating in the research received explicit instructions to avoid making their participation known to their co-workers. This instruction was explicitly acknowledged through the invitation letter and during negotiations for scheduling an interview. Although precautions were taken, total prevention of such discourse among co-workers is impractical. Therefore, the precautions to maintain employee confidentiality were made explicit to keep such conversations at a minimum.

\section{Validity}

In addition to the issue of socially-desirable responses by the research participants, other areas of validity must be assessed. The main problem area concerning validity was the accurate portrayal of employee experience due to the amount of time passed since the merger. The passage of time was especially 
problematic because the respondents were removed from consulting records from a previous era during the interviews.

Error in the recollection of detailed fact was the main impediment to attaining validity. However, during several informal conversations with co-workers, the topic of the merger frequently surfaced. In addition, explicit reinforcement of the merger is evident through various firm publications, including marketing literature and internet sources. The merger was an event bearing historical significance and identity for the firm. However, the office lacked full spatial integration for nearly two years.

As opposed to using a close-ended instrument, interviews offered greater disclosure of detail in participant responses, thus enhancing the validity of the research. An interviewer's presence at the site of data collection assures that the questions are answered thoroughly (Bailey 1994: 212). Furthermore, the use of unstructured prompts, that directly corresponded to previous literature, during the course of the interview offered respondents a chance to elaborate further upon their own commentary. By implementing this research method, the control over the process of data collection in interviewing contributed to a greater quality in the data.

\section{Coding and Analysis}

After completing the data collection, open coding ensued based on the five research objectives mentioned earlier. The interview questions described earlier corresponded to these five research objectives. Therefore, the objectives became the analytical frame for interview analysis. During the open coding phase, each 
passage was coded based on each objective and the corresponding narrative was briefly analyzed to form a particular subcategory.

As open coding progressed more thematic categories emerged, and in many cases, repetition of these categories became apparent. In the grounded theory approach patterned responses act as confirmation of social phenomena. The validity of these patterns was directly a result of sampling a wide variety of participants.

After completing the first phase of data condensing, each case was reanalyzed to further condense the data. Because the fundamental objective of the research involved organizational culture in relation to a merger, most of the analytical perspective centered on each participant's pre-merger organization. By following the open coded format of data condensing, each case was sorted based on pre-merger organization, especially when framing the code into the cultural analysis objectives of the study. Most of the analysis followed such a pattern of analysis, with the single exception of the research objective investigating employee impressions of the merger based on different occupational positions. In this particular parameter of data coding, the key criterion of sorting was initiated from purely an occupational perspective.

After the open and axial framing of the data, more careful analysis took place for the purpose of offering comparisons to the previous literature. In addition, the analysis also involved a constant comparison to the work of Max Weber and other sociological theorists. Weber's ideal-typical analysis of bureaucracy (Kivisto 2000) was a fundamental tool in the interpretation of data, with an obvious emphasis on the dialectical relation between organizational structure and culture. 
Variants to Weber's original thesis in the form of neo-Weberian paradigms also aided the analysis of data. The most helpful tool within this theoretical scheme was the concept of collegial organization, as indicated within the literature review on organizational culture. As an inherent component of professional partnerships, collegiality was found to be the primary form of organizational interaction between attorneys. However, this form of interaction between perceived equals includes a hierarchy based on specific functions and varying degrees of authority.

All data were analyzed thoroughly through the aforementioned qualitative research methods. A coherent depiction of the firm's three cultures emerged after the open coding, axial coding, and subsequent comparison to previous literature within the field. The following passages were written to provide the reader a glimpse into the organizational reality of a large full-service law firm. The data are presented in accordance with the five aforementioned research objectives and related themes that emerged directly from the interviews with employees of the law firm. 


\section{CHAPTER IV}

\section{RESULTS OF THE STUDY}

\section{Introduction}

A merger took place between the law firms of ABC Law and XYZ Law to form the new larger organization of A-Z Law. Both firms were reputable and successful in the region with an impressive network of offices located in several cities. The two firms had similar practice areas and each complemented the other in relation to unique legal specializations. With this diverse combination of legal talent, large staff, and reputation, the new firm operated as a premier full service law firm on a national level.

Of its many regional offices, the consolidated law firm integrated its combined workforce only at the Stonebridge Office, which was the organizational setting for the research. As pre-merger organizations, both $\mathrm{ABC}$ Law and $\mathrm{XYZ}$ Law possessed central offices in two different cities. Briefly after the merger announcement, an acquisition was initiated to incorporate a very small and specialized law firm, EquiLaw, into the Stonebridge Office. A-Z Law acquired this organizational unit to complement an existing department with their firm. The table on the following page is a chronology of events that is helpful in achieving a general understanding of the time frame in relation to the research. 


\section{Table 2}

\section{Chronology of Events Related to the Merger}

\section{Time (In Years)}

\begin{tabular}{|c|c|c|c|c|}
\hline-1 & +1 & +2 & +3 & +4 \\
\hline $\begin{array}{l}\text { Pre-Merger } \\
\text { Consultations }\end{array}$ & 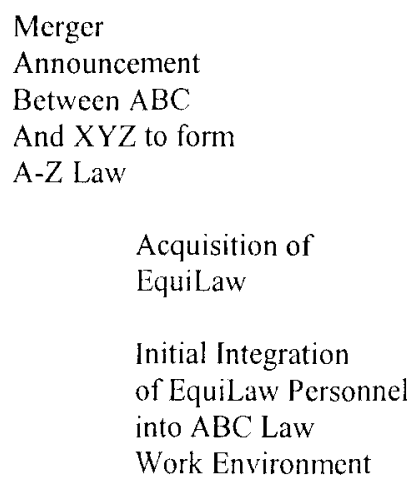 & $\begin{array}{l}\text { Full Workforce } \\
\text { Integration of } \\
\mathrm{ABC}, X Y Z \text { and } \\
\text { EquiLaw Personnel }\end{array}$ & $\begin{array}{l}\text { Rescarch } \\
\text { Begins }\end{array}$ & $\begin{array}{l}\text { Research } \\
\text { Ends }\end{array}$ \\
\hline
\end{tabular}

The table above provides a detailed chronology of events relating to the merger. The merger announcement is the point of origin for the chronology, as it is the focus of the thesis. All other events concerning the merger were constructed around this event. The information presented within the table is helpful in revealing important events and how these developments relate to the context of the research.

The main structural difference between the three law firms in Stonebridge was office size. The table on the subsequent page shows employee composition of A-Z Law by pre-merger firm affiliation. 


\section{Table 3}

Employee Composition at the Time of Merger

\begin{tabular}{|l|l|l|l|}
\hline & ABC Law & XYZ Law & EquiLaw \\
\hline Attorneys & $20 \%(10)$ & $74 \%(37)$ & $6 \%(3)$ \\
\hline Paralegals & $33 \%(4)$ & $50 \%(6)$ & $17 \%(2)$ \\
\hline Secretaries & $21 \%(6)$ & $72 \%(21)$ & $7 \%(2)$ \\
\hline $\begin{array}{l}\text { Other } \\
\text { Employees }\end{array}$ & $13 \%(4)$ & $81 \%(26)$ & $6 \%(2)$ \\
\hline A-Z Law Total & $20 \%(24)$ & $73 \%(90)$ & $7 \%(9)$ \\
\hline
\end{tabular}

$\mathrm{N}=123$

( ) Numbers in parenthesis are the tallied totals to formulate percentages.

XYZ Law was the largest contributor of personnel to the integration, as well as providing the main setting for the three-firm combination. $\mathrm{ABC}$ Law, although comparable in scale when regarding all of its offices, was somewhat smaller than XYZ Law. In addition, this office moved its operations to XYZ Law's work site. EquiLaw was the smallest of the three and possessed no networked affiliations to other offices and practiced full sovereignty over all aspects of its opcration before the merger. This law firm was also integrated at the site of XYZ Law's office.

Full workforce integration of the Stonebridge Office took two years to complete. During this period of time, arrangements were carefully conceived to facilitate the process with little disruption to daily operations. With the quality of legal talent, support staff, and technological resources available to A-Z Law, the employees of the new firm entered a new era of organizational history. With the 
strength of more qualified professionals and top tier legal experience, this new firm became a thriving network capable of producing large amounts of complex legal services. The integrated workforce of the three law firms was on the verge of a new combined effort to service clients and provide stability for the future. However, each merging firm had its own set of values, procedures, and social structure corresponding to past experience and performance. The combination of workforce led to a wide variety of sometimes conflicting viewpoints.

The composite law firm, as many employees concurred, was more a result of XYZ Law's influence over corporate culture because of firm size and stature in the Stonebridge Office. Employees from ABC Law's work environment eventually assimilated into A-Z Law. However, EquiLaw operated more autonomously within the new firm. The following sections provide insight on the integration of these three law firms. 


\section{A Cultural Comparison of the Three Integrating Law Firms}

According to Max Weber, "bureaucracy, like the patriarchal system which is opposed to it in so many ways, is a structure of the 'every day', in a sense that stability is among its most important characteristics" (Kivisto 2000: 86). The data demonstrated that XYZ Law employees saw little overall change from their premerger firm to A-Z Law. This result was reinforced through the analysis of both XYZ Law and A-Z Law. The research demonstrated a prevailing organizational culture through the lack of perceivable change among XYZ employees. Therefore, the cultural analysis of the three pre-merger organizations commences with an internal profile of the three law firms. Later within the section, the analysis focuses on the employees' external view of the other pre-merger organizations.

\section{An Internal Analysis of Organizational Culture}

The comparison of organizational cultures begins with observations provided by the employees of these organizations. By offering a view directly from these employees, the analysis provides an insider's view of each workplace.

Therefore, a pattern of common themes developed through this combined approach to analyzing organizational culture.

\section{$\underline{\text { XYZ Law }}$}

\section{General Views}

For the most part, employee work lives at XYZ Law remained unchanged after the merger occurred. Many employees of this firm recognized little change in their overall work life before and after the merger. Annie Weissbecker, a secretary 
at XYZ Law, indicated little change between the old and new firms. She stated that she "never noticed the change" and that "there were more people to get to know." The work life of attorney Chris Tennant also revealed a lack of change:

Is it sufficient to say very similar to the way it is now? Generically, it's...show up for work at the same time, do the same functions that I would have done had I been at XYZ Law, as a six-year lawyer. Those roles I think are the same as they are now or would have been the same had the merger not happened.

This theme of a static work environment after the merger was instrumental in developing a lineage between XYZ Law and A-Z Law, as well as differentiating the work environment between the merging entities.

The size of XYZ Law's Stonebridge Office and the associated strength related to a larger organizational setting was integral in the analysis of its culture. Participants indicated a greater feeling of significance during the previous organizational configuration. In reference to the entire network of XYZ Law's offices, many employees revealed a sense of empowerment before the merger. As the largest of the three integrating firms, employees of XYZ Law viewed their firm as a more powerful entity. As XYZ employee Bryce Campbell explained:

The Stonebridge Office at XYZ Law was the second largest out of the five prior to the merger. It was the second office in charge and worked a lot with the Flower Mountain Office, which was the main corporate headquarters at the time. Stonebridge has been set back a little bit on the food chain, if you will, to where a lot of people found it, for a lack of a better word, annoying that our voices are not heard like it used to be. So before, the Stonebridge Office was a big office compared to the rest.

The previous passage indicated a sense of organizational prowess XYZ Law felt before the merger. As a large office in the organizational scheme, employees regarded the Stoenbridge Office as a prominent entity within the region. Some employees felt XYZ Law's client base allowed it the luxury of standing alone, rather than being viewed as a minor satellite office of a larger centralized office. 
The fact that this firm was larger than the two firms with which it merged also had social implications, especially in regards to personal contact. The historical transformation of this once small law firm into a larger entity was a key component in influencing the amount of social cohesion within the organization. In its earlier form, XYZ Law possessed many cultural attributes of a small firm. As partner Walt Orton demonstrated, office size had an impact on the organizational culture of XYZ Law:

When I came here in ' 84 , there were six lawyers and about seven or eight employees. So it's changed a whole lot. We used to play tennis on Thursdays and golf and things like that, but now everything's going so fast. The bigger you get, the busier you get. It's proven in the legal profession.

XYZ Law grew significantly during the previous ten years. As a distinctively corporate entity, it possessed a very developed support staff and a strong clientele. Furthermore, its bureaucracy within the Stonebridge Office was largely due to the total number of employees and a functional need for control. The idea of being active throughout the day was reinforced by many former XYZ Law employees.

\section{Billable Hours}

According to the perceptions of XYZ Law paralegals and attorneys, standards for billable hours remained constant, even after the merger. Large profitable law firms generally require more billable hours to meet financial goals. The demand for more billable hours, was an additional component of XYZ Law's culture. Previous standards for billable hours were viewed as 'normal' to these employees, as attorney Chris Tennant explained rather simply:

I think they're the same from my perspective...my feeling about current standards would be the same for the prior standards, which from my perspective are very reasonable. 
Rose McMullen, a paralegal for XYZ Law, also found the standards to be quite normal based on the previous model for billable time. She added that the per annum standard, according to other attorneys from XYZ Law, could have been increased due to the size and scope of the firm:

I think they're pretty normal. My boss thinks the billable hours are on the low end. My billable requirements are 1600. Steve Winford (an XYZ Law partner and colleague) told me they should be higher, where associates have 1800 . With them, you really need to be shooting for 2000. I think we're probably getting off lucky, if you base on who I work for.

Overall, the billable hour component of the cultural analysis provided a key perspective behind the culture of XYZ Law: it is a large firm with an already high billable hour requirement that can be increased.

\section{Pro Bono Opportunities}

Performing altruistic legal work for the benefit of the community is one function of the attorney's legal practice. However, attorneys are not required by the bar to provide such work. As a part of the attorney's work experience, the application of pro bono services functions as a liaison between those segments of society that require legal services and quality attorneys that can apply sufficient legal knowledge. This is one area of analysis that is imperative to the understanding of both the legal profession at large and the operating philosophy of law firms.

As a partner, Walt Orton acknowledged the influence that law firm size bears upon the pro bono aspects of XYZ Law and how he defined the type of work attorneys receive at $\mathrm{XYZ}$ Law:

Bigger firms have a tendency of being busier and having more quality work. It's just a fact of life. They don't give as much of their time as a smaller firm, which are more inclined to offer work to the community. They are more segregated emotionally and socially.

The culture of XYZ Law in relation to pro bono work left attorneys with the initiative to approach pro bono work. The environment of the large, vivacious law 
firm left little available time for non-billable related work. Therefore, a passive encouragement was perceived by attorney Chris Tennant:

If a person does engage in it, they are more than welcome and encouraged to do so. If a person does not express a desire or reach out to try to do more or any, I don't think there is an active push to do so. It's certainly not discouraged. Anybody that wants to do it, they do. If somebody does not want to do it, it's not forced down their throat. That's the way it is now and was before the merger.

\section{Summary}

As described by its employees, XYZ Law was a large organization built upon the foundation of quality legal work, high standards for billable hours, and a bottom-line approach to the practice of law. The work environment was described as hectic and contrasted with the setting of a small office consisting of more intimate relations among employees. Changes to the work environment as a result of the merger were unrecognizable. The changes noted in the previous passages indicated a sense of growing larger in size but possessing similar characteristics to the pre-merger organization. This revealed a dominant organizational culture, which will be revisited in the following chapters.

\section{ABC Law}

\section{General}

Contrary to the perceived role of XYZ Law's Stonebridge Office, ABC Law's office in relation to their own organizational scheme was marginal. However, in this instance the size of office influenced work processes. ABC Law employees regarded their smaller office as an organization characterized by intimate contacts and casual attitude once tasks were completed. As employee Glenn Baker remarked:

Big atmosphere change. Actually, $\mathrm{ABC}$ Law was a lot more laid back. Probably because of the number of employees in our satellite offices. As compared to XYZ, it was probably a 
third (of the size). It's down to a third of the employees we have now. There's a big change in philosophy. We were more about if you get the job done, you can do whatever. You didn't have to necessarily be in front of the computer looking like you're busy at work. You can chill out, as long as you got your work done. It was just a lot more laid back.

The acceptance of idle time after the completion of tasks revealed a sense of collective trust of employee judgment. Another employee, Samantha Stover, provided a more detailed account of the ABC Law work environment:

We were a branch office of the main office in Redland Heights. We were small compared to the Redland Heights Office. We were like family. The attorneys respected the support staff more. And treated them with respect. If you got your work done--I mean you couldn't come in at nine and work until three--but as long as you got your work done, they were flexible with you regarding doctors' appointments and things like that. You could take your hour lunch whenever you wanted. It was more flexible. It was calmer.

The previous passages revealed an altogether different work atmosphere than XYZ Law. Evidently, office size was a great determinant of how the organization functioned. In the large, bureaucratic law firm like XYZ Law, attorneys' professional autonomy was compromised under the pressure to meet high standards for billable hours. As a smaller firm, attorneys at ABC Law enjoyed a high level of professional autonomy and flexibility in a less demanding work environment. Within the literature, the size of law firms and their corresponding attributes are well-noted. This was another example of the bearing law firm size had upon the perception of work environment.

\section{Billable Hours}

Billable hour requirements and their fulfillment are not only a matter of policy, but also one of economic survival for law firms. Standards for billable hours for $\mathrm{ABC}$ Law were emphasized, but not as high as the standards at XYZ Law. Firms configure billable hour requirements based on their own philosophy to meet financial needs. Paralegal Linda Jones shared this view: 
I don't think they were as high. They were strict, but they weren't as high as the merged firm. I don't think they were as demanding at the old firm.

The adoption of a uniform billable hour standard for employees is consistent with more developed law firms covering a wide area of practice. As indicated by the cultural profile of XYZ Law, employees viewed little difference between the old and new firms' billable hours, and thus, felt the demands for high billable hours to be normal and reasonable.

\section{Pro Bono Opportunities}

Due to the constraints of sampling a small subpopulation of attorneys from $\mathrm{ABC}$ Law, the comparison of pro bono opportunities was not achievable.

Therefore, the analysis continues without investigating this parameter of the $\mathrm{ABC}$ Law firm's culture.

\section{Summary}

$\mathrm{ABC}$ Law was a busy, yet less formal work setting than XYZ Law. When comparing their pre-merger firm to the post-merger synthesis, ABC Law employees felt a significant change in the expected tempo of work required by the new firm. A smaller 'family feel', lower billable hour standards, and perceivably calmer environment were all cultural attributes of this pre-merger law firm.

\section{$\underline{\text { Equilaw }}$}

\section{General}

Although the smallest law firm, EquiLaw brimmed with activity within its unique area of legal expertise. Partner Pamela Wolczak revisited the work environment in detail:

Before the merger it was very busy, very erratic as far as the hours. Often he (the founder of EquiLaw) would say something needed to be done at four o'clock and you had until the next 
day or two days after that, which means you would work until then, until it got done. He answered e-mails asking about cases, and this is nothing derogatory about him, information asking about cases, if I'd heard about these cases. Information I had to have to proceed. He had e-mails, sometimes sent between four thirty, five, or six. And so, I had to wait for those, which meant there was someone working there all the time. It was seen as a twentyfour hour firm because you could always get one of us at the office.

Ms. Wolczak explained the hectic nature of working closely with the founder of EquiLaw. Ms. Wolczak possessed a high level of responsibility and dedication to the most influential attorney at EquiLaw. Her close work relationship with the charismatic founder gave her an important role within this law firm and it is this role that frames her observations about A-Z Law's bureaucracy in later parts of the analysis.

The next area involving EquiLaw's unique workplace related to the concept of individualism. In his analysis of organizational culture, Hofstede (1994) identified five elements of a cultural orientation model. The first element involves the individual/collective analysis. Absent a developed bureaucracy like its larger merging counterparts, EquiLaw exuded more of an individualistic spirit in the practice of law:

Prior to the merger everything was very flexible, a lot more flexible as far as time and all of that. The responsibility was, in a way, greater. It was just very different. There was a premium on quality and quantity of work rather than conforming to a bureaucracy or to a structure that, to me, doesn't really matter. It was just more individualistic. There was no supervision.

Again, size of firm was relevant to the view of firm culture. In this case, the lack of an extensive network of collaborating attorneys led to a more individualistic practice of law and feeling of attachment to her immediate colleague. The individualism of professional autonomy existed in a structure of shared destiny (profit sharing). The collegial nature of this smaller firm was perceived as very strong: 
One other thing too is it was more helpful, the prior structure was--because I am very detail orientated and he (founder of EquiLaw) was more open, broad spectrum planning--he did not see the box or recognize it or be inside of it. I missed that, because I don't have someone at this point where I can bounce things around.

The strong collegial nature of this interaction was viewed with fondness, and, to a degree, sadness that such a work relationship was absent from her current work environment.

\section{Billable Hours}

Requirements for billable hours at EquiLaw were stringent, yet reflected an underlying philosophy different from the standards of XYZ Law. Although the standards were on the same level, a distinction between billing and actual collection was provided by Ms. Wolczak:

They were about the same. The difference, of course, with EquiLaw is that after you met your hours, we shared profits equally. So that was more of an incentive for collection. It was more of a realistic bottom line rather than just putting down hours on paper whether the client pays for the services or not.

In the above passage, Ms. Wolczak noted a more effective method of obtaining billable hours. In law firms, a difference exists between hours billed and actual collection. Furthermore, clients review billing invoices with the utmost scrutiny and may not agree to pay for some services. Within the literature review, normative authority was discussed in detail, especially in regards to compensation as a form of establishing legitimate authority (Hodson 1999: 296). Based on this concept, Ms. Wolczak revealed a contribution to this understanding of legitimate authority. The focus on actual collection for the production of profit created a feeling of just compensation, and inevitably provided incentive for good work. 


\section{Pro Bono Opportunities}

The concept of individualism again surfaced in the cultural analysis of Equilaw. Contrary to XYZ Law's passive stance on pro bono work, EquiLaw's figurehead founding partner expected attorneys to do pro bono work:

It was a little bit better because we did a lot more religious charity. He, it was more expected and It was more individual and he knew what you brought to the table. It's not that other things are not, but it wasn't discounted. It wasn't like it didn't hit the radar. I think it was more, at least it was more recognized. At least you didn't feel like you didn't do anything. It was recognized.

As inferred by the above passage, the recognition of pro bono work and its perception was derived from the values of EquiLaw's charismatic founding partner.

\section{Summary}

As the smallest merging entity of the three integrating firms, EquiLaw was a law firm brimming with activity to a point where conventional working hours were the exception. The lack of boundaries on professional service was offset by the high degree of professional autonomy and sense of solidarity--underlined by the practice of profit sharing--among the attorneys. The collegial atmosphere between attorneys was strong due to such a small work setting. In addition, the absence of a developed bureaucracy allowed for a closer relationship between few attorneys. Incentives were established and profits shared by a small number of attorneys. The firm was individualistically inclined in the practice of law and possessed the flexibility to meet the ever-increasing demands of the legal services industry.

\section{Views of Organizational Culture from the Outside}

An analysis of the interaction of employees affiliated with the different premerger law firms was vital to develop a more valid understanding of the cultural attributes of each firm. The interaction of organizational cultures exhibited even 
more unique instances of cultural difference than the accounts above revealed. It was this aspect of cultural analysis that provided for more insightful cultural comparisons.

\section{XYZ Law Impressions of ABC Law}

XYZ Law employees viewed their post-merger colleagues through the unique cultural lens of their own work setting. As more interoffice contact occurred, XYZ Law employees gained perspective on the work environment of ABC Law. Many XYZ Law employees felt the impact of XYZ Law's size in relation to the merger. The theme of XYZ Law's Stonebridge Office dominance in the structure prompted a feeling of sympathy towards ABC Law, as secretary Annie Weissbecker stated:

They were a smaller office. They were a satellite office out of Redland Heights, where XYZ Law in Stonebridge could stand alone. We were not as big as the Flower Mountain Office, but we were a good size Stonebridge law firm. So it probably was harder for them. They were in a casual setting, very friendly. They had people in Redland Heights that were not watching anybody. It was probably harder for them.

The end of the previous passage reveals a very interesting reference to interoffice monitoring, which hints of a difference in the development of a bureaucracy between the two firms.

As indicated by both the ABC Law and XYZ Law employees, ABC Law's work environment was described as more relaxed and casual. Interestingly, a difference in work ethic was perceived by XYZ Law employee Bryce Campbell. The more casual setting of ABC Law conflicted with the steadfast work ethic of XYZ Law:

Probably, on a level where I had to work with these people, I still felt like I didn't want to. When they first started talking about the merger, I was in a previous position and I didn't want to do it the way they did it because I felt like we worked harder than they did. They were getting paid the same, sometimes they were paid more than we were. 
In the above passage, Mr. Campbell expressed a sense of economic injustice in reflecting upon the differences in work and compensation at $\mathrm{ABC}$ Law and $\mathrm{XYZ}$ Law. As an additional sign of a different work environment, XYZ Law paralegal Rose McMullen perceived more equality of social status between ABC Law's paralegals and attorneys because they had window offices. In organizational settings, the types of offices occupied by employees are a direct reflection of status. Artifacts are the most concrete evidence of human activities in an organization (Alvesson and Berg 1992: 80) Size of office, interior décor, and location are vestiges of social status within an organization. Ms. McMullen perceived hardship and cultural difference through this reasoning:

Because you have the culture of XYZ Law, Stonebridge Office, and you have the culture of ABC Law, Stonebridge Office. Things were so different. They had a smaller office. All their paralegals had window offices. None of our paralegals had window offices. That's just one example. Their paralegals were not really happy to come over and not have a window office, which eventually got us all window offices.

Although the $\mathrm{ABC}$ Law office was smaller in size, the above narrative states a departure from the XYZ Law perspective on paralegal offices. In this particular case, ABC Law's culture along with XYZ Law's willingness for change was instrumental in forging a lasting cultural contribution to A-Z Law.

\section{XYZ Law Impressions of EquiLaw}

Described by its own employees as a workplace organized around the concept of individualism, EquiLaw was regarded as being a small practice group led by a charismatic figurehead attorney. As such, EquiLaw had a rudimentary apparatus of authority while control over the firm's operations was vested in two founding partners and a small group of other attorneys. This firm was regarded with 
reverence and, at the same time, apprehension. XYZ Law secretary Annie

Weissbecker reinforced this notion:

When Vincent first established his office, it was the place to work. The word was that he was paying his employees way higher than anybody else. They had these great benefits, they got all these corporate special things. And if you could get into that firm, you wanted to get there. But he's also unstable. He's had three or four law firms with his name on them.

The prestige of this attorney and his work group bore an impact on how the employees view this organizational entity. The relative autonomy of this work group within the larger post-merger work environment became an issue with many XYZ Law employees. This autonomy coincided with the EquiLaw description of an individualistic orientation, as Bryce Campbell illustrated:

When Vincent brought his group in, he made it immediately clear to everyone that he is Vincent Paulsen and (imitation) "This is my group. My group comes and goes with me. I want my group working specifically with my people. If you want to adapt with the way we're doing it, fine. If you don't, that's fine too. I'm going to keep my software, I'm going to keep my procedures."

Maintaining autonomy from a cultural standpoint corresponds directly to Schein's (1985) definition of culture. The shared basic assumptions learned by this group over the course of time to respond to external challenges was exhibited by this need to maintain EquiLaw's cultural identity. Indeed, Mr. Campbell observed EquiLaw with scrutiny as autonomy and preservation of culture escalated through different means:

Vincent, at all times, wanted to stay on his own floor, away from the rest of the office. He wanted to keep his people there and he did not want to have his carpet redone to match the rest of the firm. He didn't want paint or decorations to match the rest of the firm. He wanted to stay in Vincent Paulsen's office, but also get the benefits from A-Z Law.

Secretary Gwen Ribbendorf questioned the motivation behind EquiLaw's

unwillingness to integrate into the larger organizational setting:

Well, they were a little different. They merged with us, but still had their own little group. ABC Law never did that. When we merged with them it was one big group. It always seemed like EquiLaw never did that. They just kept to themselves and had 
their own little meetings. That was different. It was hard to approach them because I didn't know if they really wanted to be. I never understood why they really wanted to merge. I never understood why they would want to be there.

The above narrative is a prime example of clashing cultures. XYZ Law's developed system of hierarchy, large interacting support staff, and reliance on more active modes of authority was in direct contrast to the independently minded and less structured work environment of EquiLaw. Within Schein's (1985) definition of culture, both firms view the other from their own cultural perspective, a result of systematic patterns of beliefs constructed over the course of each firm's unique history. Therefore, the long -term success encountered through this prevailing system of belief is deemed effective and functional. Because employees of each firm operated in accordance with these beliefs, stark differences became evident.

\section{ABC Law Impressions of XYZ Law}

ABC Law's office, as described by both their own employees and XYZ Law personnel, was a relatively casual setting where legal/non-legal hierarchy was less established. As the larger firm in the merger, XYZ Law possessed a developed bureaucratic organization, rigid employee distinctions, and a need for controlling the work environment due to its size. As a smaller firm, $\mathrm{ABC}$ Law employees shared a closer camaraderie, which was evident in informal events. Several ABC Law employees revealed this when describing their initial encounters with XYZ Law support staff. Secretary Wilma Dahl remembered the encounter in detail:

I remember us having a lunch where we had it at the old $\mathrm{ABC}$ Law Office and invited everyone over from $X Y Z$ so we could feel a part of the team. And I remember when they walked in we had tables everywhere. They said, "Where does the staff sit?" And we said, "What do you mean? " And they said, "Well, we don't sit with the attorneys, do we?" So we said, "Well, yeah. Why not? I mean, you don't sit with the attorneys?" They said, "No. We don't do it like that over here." So we knew right away they didn't have as cozy of a team environment as we were. 
Interestingly, this is one example of $\mathrm{ABC}$ Law's weaker cultural adherence to a

hierarchical organizational structure. On the other hand, XYZ Law employees

exhibited more of a formal orientation towards attorneys. Part of the casual

component of $\mathrm{ABC}$ Law described by all participants in the research included a less

formal view of social relations within the organization. $\mathrm{ABC}$ employee Samantha

Stover also indicated such a orientation:

And my first impression was when we had people over to eat...the secretaries of XYZ Law were aware of where they were supposed to sit. I remember actually trying to get them to sit down with us while we were sitting at a table with attorneys. They were very abrasive.

Some of them told me it (secretaries sitting together with attorneys) would not exist in their firm. The attorneys and higher-ups do not mix with the support staff. There was a definite class distinction. That's not how it was at $\mathrm{ABC}$ Law. We had to work together. I went to lunch with attorneys. That was not a big deal and nobody made a big deal about it.

Social cohesion on an informal level without emphasis on status distinctions was a function of a smaller office. As Ms. Stover said, working together was regarded as more of a communal experience that bonded employees beyond mere actors within economic relations. In contrast, that the XYZ Law employees felt a need for formality in organizational settings and relations devoid of a sense of community was met with astonishment by the $\mathrm{ABC}$ Law employees.

\section{EquiLaw Impressions of XYZ Law}

The most visible difference in organizational culture during the merger existed between EquiLaw and XYZ Law. EquiLaw's work group remained intact and operated in familiar work arrangements within the larger environment. The cultural interaction from the perspective of an EquiLaw employee revealed cultural divergence within the new firm.

As an attorney at EquiLaw, Ms. Wolczak spoke of a smaller, more individualistic work environment. XYZ Law, as regarded by their own employees 
and $\mathrm{ABC}$ Law staff, tended to possess a larger office, more developed bureaucracy

and an adherence to the social hierarchy. Within her work environment at EquiLaw, decision making did not follow a strict hierarchical process. Instead, decisions were made in a more autonomous manner among individual attorneys. When asked to give her assessment of EquiLaw's role within the context of A-Z Law, Ms. Wolczak responded:

Gone. I think gone because, and this is exactly what I told Vincent: "You're used to making decisions on your way to work. You're not going to do that." Being with him for eight years, and that's probably part of my problem too, looking at this 'in the box' thing. I think it is misconstrued as being fragmented or not a team player. I am not sure. Eventually, seeing how it became, it was completely different fitting into this organization.

The following depiction of the decision making process can be interpreted within Weber's analysis of charismatic authority (Kivisto 2000: 91). EquiLaw conducted operations in a manner seemingly unorthodox if looked upon by members of a highly structured social setting. With decision making done in transit, as Ms. Wolczak explained, the individualistic ability of the charismatic leader was a matter of conventional routine. A formal hierarchy and existence of a large network of colleagues was absent.

Ms. Wolczak's comments supplemented this cultural dynamic through the theme of bureaucracy. This attorney felt the XYZ Law's system was blindly rational, leaving her on the brink of frustration:

I don't like the XYZ attitude. I feel that I have no direction and I can't get a rational explanation other than, "That's the way it's always been." We've worked very hard to integrate and be a part of this new entity. I tried to divorce myself as much as possible from EquiLaw because it's not a good thing. That was very difficult because we had difficulties with billing and all this and that. I saw that kind of attitude very detrimental to us blending in and being harmonious with everyone else. So I tried very hard to make the process less painful.

The loss of organizational identity was evident for this employee of EquiLaw.

Although fondly recollected by Ms. Wolczak, the EquiLaw precept of flexibility 
and individuality clashed with XYZ Law's more bureaucratic system of legal practice. In this mode of acquisition both the acquiring and the acquired organization preserve their organizational identity, whereby either harmonious coexistence or collision between cultures are outcomes (Nahavandi and Malekzadeh 1988: 81). Through the narrative provided by Ms. Wolczak, cultural collision appeared evident. 


\section{The Integrated Law Firm: A-Z Law}

As previously demonstrated in the cultural analysis of the three pre-merger firms, XYZ Law was demonstrably similar to the new law firm. Office size was a key component in this understanding as several employees from various firms affirmed the correspondence between office size and formality within the new work environment. This was especially evident in the themes emerging from narrative related to structure, individualism, and organizational expectations. Although some degree of change was noted, the underlying fundamental system of values of XYZ Law remained unchanged. The first section of this chapter provides evidence of XYZ Law's cultural/structural contribution to the merger.

\section{XYZ Law's Enduring Legacy}

The perception of executive leadership was important to the understanding of enduring components of organizational culture. Partner Walt Orton of XYZ Law demonstrated a feeling of control over the integration process:

I think XYZ Law were the aggressors. We were the ones that went out and sought actively. We felt like in order to be a player in this area and be a regional law firm, we had to find somebody. We had to put it together. I think [XYZ Law Executive Partner]'s leadership was far stronger than the $\mathrm{ABC}$ Law leadership. We brought together several areas of practice and they complemented ours. They were different cultures as far as they viewed compensation and that type of thing. But we revamped the compensation setup after many discussions. I think we brought more than they did to put it together, but it's been a nice mix after that.

Negotiations are an integral component of the merger process. According to Mr. Orton, integration activity was mostly initiated by XYZ Law. Furthermore, a difference of organizational views was negotiated on a fundamental level between $\mathrm{ABC}$ Law and XYZ Law in regards to issues of normative order such as compensation. After such issues were resolved, assimilation to the new office, dominated by XYZ Law, took place. 
New firm expectations were also seen to be similar to previously acceptable

standards at XYZ Law. Attorney Chris Tennant saw only a subtle change to the law

firm on an attorney level:

I think it's unchanged from my understanding of the expectations under the XYZ Law system. I think perhaps there might be a change to a more team-orientated approach in terms of originating and generating new business towards the law firm under the new regime rather than the XYZ Law model. I do not know how effective the team approach has been. From my perspective, it has not been remotely effective, but I don't know if I am speaking ignorantly since I don't know about the other parts of the firm. Maybe they realize a whole lot of efficiencies and generated new business because of it. I don't know. The expectations are similar except perhaps there's a push to develop new business from this perspective.

This perception is in stark contrast to that of the employees of both ABC Law and EquiLaw who saw the merged entity as an entirely new place to work. Secretary Janine Ragowski of XYZ Law regarded the new law firm with a sense of familiarity:

I really don't see much of a difference. The only difference I notice is the loss of some of the benefits that we had. It's not really an ongoing thing with me. I look at not the petty things, but the loss of three days of sick or personal time is significant. The fact that I now have to maybe enter a different number on the copier--those things don't bother me. I don't think I have any petty stuff. I try to focus on the significant, and then just deal with it and go on. What's the sense? You're not going to change it. Deal with it and move on.

Within the highly structured bureaucracy of XYZ Law, Ms. Rogowski believed the changes in her work life were insignificant. On the contrary, ABC Law employee

Samantha Stover felt a loss of identity of her pre-merger organization:

I don't feel like ABC Law has any identity at all. Well, not in this office. Maybe the people in other offices feel differently. But not in this office. Not at all.

In addition, some XYZ Law employees found that the A-Z Law firm's Stonebridge Office was a busier, larger place than their former workplace. Moreover, ABC Law and EquiLaw employees integrated into the original site of XYZ Law's Stonebridge Office. As XYZ Law paralegal Rose McMullen regarded XYZ Law within the context of A-Z Law: 
The very same way. Maybe as I said earlier. The same attorneys that are here, except for the ones we've added, which is like three people--it is XYZ Law.

The fact that XYZ Law employees saw their law office from an expansion standpoint was a recurring theme standing in contrast to the employees of the other firms. The power of influence held by XYZ Law during the integration of the Stonebridge Office was felt by all employees, irrespective of hierarchical status. XYZ employees felt their firm absorbed several individual employees rather than two law firms. Secretary Maureen Yates described the maternalistic image of XYZ Law:

From XYZ Law to A-Z Law, I see XYZ Law being the mom and they took in and merged with the other company. I don't see a whole lot of difference, only that they [XYZ Law] had to get larger. As far as employee handbooks and things being spelled out a little more... benefits. But I don't see a whole lot. I feel like they brought in their other firm and made them XYZ Law rather than the other way around.

The reality of an XYZ Law majority population within the combined office's workforce was felt by many A-Z Law employees. Within the Stonebridge Office, employees of EquiLaw and $\mathrm{ABC}$ Law revealed a sense of minority membership. ABC Law employee Samantha Stover perceived that ABC Law employees were second-class citizens relative to XYZ Law:

There was a problem that there's a feeling amongst my former firm that...that they're trying to clear out our firm. With so many former XYZ people... that we're the red-headed stepchildren.

As the passage indicates, feelings of inferiority abound within the combined law firm directly because of the issue of size and contribution to the firm. Although the new organization's other offices accounted for contingencies such as a uniform financial structure and compensation, the Stonebridge Office was the lone site where full office workforce integration took place. Office size and personnel composition were recurring themes in the accounts of all employees. 
The previous paragraphs were arranged to provide coherence in the understanding of the cultural influence XYZ Law exerted within the context of the new law firm. This apparent outcome of the merger was a uniformly described reality from a diversity of viewpoints. By using such an illustration by A-Z Law's employees, the new firm's culture can be regarded as a further incarnation of XYZ Law's culture, albeit in a more complex setting. The confirmation of this organizational reality was achieved directly through a consensus: many XYZ Law employees did not feel a profound organizational change while employees from $\mathrm{ABC}$ Law and Equilaw found the opposite to be true.

\section{Inside the Larger Office: An Expansion of Practice and Prestige}

\section{Pride and Excellence}

Employees of A-Z Law, the combination of all three firms, regarded their organization as a futuristic law firm that was well-equipped to enter a new age in legal practice. As a larger corporate entity, employees felt on the 'cutting edge' of client service. The expansion widened the area of legal practice significantly, thus increasing the amount of resources available on site. Competing in such a knowledge-based industry, A-Z Law grew exponentially in overall legal expertise. As former ABC Law secretary Wilma Dahl stated:

I do like the way they're developing certain areas of practice and the marketing that they use. It seems like they're on the cutting edge as far as law firms go. I am proud to be part of ii.

Being part of a large operation instilled a sense of greatness in employees.

However, such satisfaction derives from competence. As a former ABC Law employee, Glenn Baker felt a new dynamism within the new office: 
I think they have pretty high expectations of their employees. Both firms were pretty successful. Probably eighty-five to ninety percent are $\mathrm{ABC}$ and $\mathrm{XYZ}$ employees, so they know what to expect. So when we came together we were like, "Wow, we're a larger firm now, we have more resources, we have more people with expertise. So we have to step it up." I believe they have very high expectations of their employees. And they've accepted it too.

Exerting one's best effort for the welfare of the client was also expressed.

Maximum dedication and commitment to work were regarded as being the central goals of the firm. Former XYZ Law paralegal Rose McMullen said:

I think they expect their employees for the most part, I hope they expect their employees, just to be the best they can be. That they are going to give our clients the best service we can. That's really the only thing that keeps clients coming back and it's continuing to grow, so we can get benefits and bonuses. It really is important that everybody do their best.

That's all they expect.

The scale of the new business enterprise influenced the views of A-Z Law

employees. A sense of personal excellence derived from operating on a large scale

and providing good service. Performing at one's fullest capacity was an expectation

common within A-Z Law. Attorney Pamela Wolczak recognized the need for

excellence, but within a context of more hours and more money:

I think they expect excellence. I think that is a common thing. I'm not really sure if there's any...I know when it comes to attorneys and staff, it may be different. I think they expect good attitude. They expect big hours, big billing, big money, bigger organization.

Further corporatization of the Stonebridge Office brought importance to unwavering individual performance. In conjunction with Schein's (1985) definition of culture, merger acculturation sometimes leads employees to impressions that focus upon market success as an external influence over their organizational culture. This leads to employee feelings of innovation and success (Kanter 1984: 151). The bottom line of providing client service through earnest effort was widely recognized by $A-Z$ Law employees as a firm trait. In addition, the increased pressure to perform on a larger scale, as an external force influencing cultural adaptation, led to a requisite 
need for employee dedication. The sense of duty to perform was deemed a

praiseworthy distinction corresponding to the new stature of the law firm.

\section{Stability of Normative Order}

Within the context of a large office, many employees regarded strength and stability to be a prevailing organizational characteristic. This arrived out of the feeling of better adaptation to the competitive industry as a whole. Secretary Annie Weissbecker offered her view on stability:

With size comes stability. You don't have to worry about your paycheck, it's there. Your benefits are better. Heath insurance, you know? Those things. When I first came to Stonebridge I started working for a law firm. I just graduated college and wanted to go to law school. I got accepted, but I needed some money. I didn't care what health insurance was, I never used health insurance. Now I care. Now it's different.

As noted, the overall condition of normative order within an organization rests upon the establishment of legitimacy. High salary, good fringe benefits, job security, and other core areas of concern to employees solidified an impression of legitimacy in the minds of A-Z Law employees. This was further explained by secretary Wilma Dahl:

Benefits can be a better option for employees because you have more numbers. I hate to use the word 'job security' because as soon as I say that I'll get a pink slip. But I feel somewhat more secure because it is a large company that is diversified.

The above narrative represented the importance of organizational legitimacy.

Employees fearful of job security, as Ms. Dahl indicated, may find an inconsistency between the exchange of individual excellence and the organizational recourse. The growth of the law firm led to a need for maintaining normative order between employees and the organization.

Large companies in the information technology industry also receive such views from employees. Employees regard important benefits and greater fringe 
benefits as great indicators of stability (Hamada and Sibley 1994: 124). However,

within this favorable view of larger companies arrived an accompanying feeling of

bureaucratic rules limiting the process of goods to the market (1994: 124).

\section{Bureaucracy}

Organizational expansion led to a need for more control through

bureaucratic regulation. Thus, the regulatory mechanism of bureaucracy to sanction certain types of behavior is directly rooted in the material needs of the law firm.

Partner Walt Orton perceived a strong need for control, especially when considering billing procedures:

I think there's more efficiency, because of the administrative part of it. The cost if you delay. If you have four hundred partners and miss a half an hour a day, you can see how that multiplies two hundred hours a day. That's a lot of money. So it's been emphasized that you get your time in and your billable time and if you do that, we will become a more profitable business and reap the benefits. I think everybody's making more money overall than before.

The increased implementation of bureaucratic control over certain areas of the firm was vital for maintaining consistency in employee behavior. On such a large scale, A-Z Law required uniform standards of conduct to meet its financial needs.

However, the financial and cultural need for control had limitations on the individual creativity of employees, especially in regards to individual autonomy, as employee Bryce Campbell noted:

A-Z Law's expectations of Administrative Staff employees: they don't really allow for free-style thinking. They're not really adaptive to people making a change on their own. What I' $m$ thinking about is an office manager who was here before. She had some ideas about running the office in ways that were completely different than I've seen. They were frowned upon harshly by everyone in the office. Nobody thought she was running the office correctly. They lost confidence in her as a leader. It goes to show they don't want you to stray from the norm. The expectations are more strict than they have ever been in the past. I think that's a result of the merger from becoming a corporate business as opposed to a smaller office. You're expected to do what you're supposed to do and don't ask any questions. 
The passages illustrate Max Weber's analogy that bureaucracy is an "iron cage"

(Farganis 1996: 113). Although bureaucratic control is instrumental in determining employee behavior for meeting organizational needs, it can also be detrimental on an individualistic level.

The augmented development of bureaucracy at A-Z Law also led to a perceived sense of inefficiency at the top tier of executive and administrative organization. With an increase in the amount of prestigious partners upon merging, the power structure within A-Z Law became more democratic. This new power structure grew larger and included partners of both firms. However, the structure lacked efficiency in decision-making, as Walt Orton described this new phenomenon in detail:

As all corporations, you have many chiefs and not as many indians as you need. The negative would be too many chiefs running around in both outfits and we need to trim that down, and we're trying to as far as getting a new management set up. I think that is a negative when you have certain people who are used to running something, you join forces and allow them to co-manage. That's fine, but up to a point. But after awhile, you have to run it like a business. That's the hurdle we have right now. We don't need two managing partners. We need one Chairman and a Board of Directors.

As an adaptation to the merger, Mr. Orton felt that the willingness to share executive positions was committed in an effort to form an egalitarian principle between ABC Law and XYZ Law. However, A-Z Law's new structure created a culture of power sharing at the executive level, which appeared wholly inefficient to Mr. Orton. Inefficiency was also perceived at the administrative level, where expanded bureaucratic functions were viewed with skepticism. As attorney Chris Tennant stated:

One effect the merger did have on administrative issues is that it, from my perspective, created additional administrative tasks and therefore jobs by--I don't know if it unnecessarily complicated or complicated things that needed to be addressed by additional tasks and jobs. I don't know if the top end of the administrative ladder is quite as effective as it used to be. 
The growth of the law firm created a more complex work environment with the addition of employees and individual offices. Weber's view of rational-legal authority as the dominant model of authority in modern capitalist societies (Ritzer 1996: 238) is uncannily applicable to the growth of this law firm. In an effort to adapt within a very competitive industry, the firm attempted to rationalize and modernize its operation. In effect, the infrastructure of the firm grew as the need for control increased. However, the need for increased regulatory functions was mitigated by a cultural penchant preferring decisive action at the executive and administrative level. Indeed, the cultural attribute of excellence and working in an exciting dynamic environment were at odds with fulfilling the new bureaucratic needs of the firm.

\section{Legal/Non-Legal Hierarchy}

A formal adherence to the legal/non-legal divide existed within the organizational culture of A-Z Law. Most medium-size and large law firms possess such a division of labor between legal tasks and administrative tasks. However, the characteristics of this socially arranged distinction vary in different law firms and in relationship to their unique historical contexts. An example of such a cultural difference was illustrated earlier between the employees of ABC Law and XYZ Law during post-merger gatherings. $\mathrm{ABC}$ Law employees felt less of an occupational division than their XYZ Law counterparts, leading to assumptions about XYZ Law's adherence to formal social relations and strict status classifications. 
A-Z Law employees felt a prevailing legal/non-legal division within the Stonebridge Office similar to the cultural dynamic of XYZ Law. The system of hierarchy had a bearing on the expected conduct of employees. As stated earlier, ABC Law employees regarded the dividing line between legal and non-legal employees to be less rigid, although such a hierarchy existed. A-Z Law employees perceived an ever-present hierarchy, which led to employee impressions of attorneys in a certain light. When describing a recent meeting among all A-Z Law employees, Gwen Ribbendorf revealed a strong sense of distinction between attorneys and legal staff:

\begin{abstract}
In my class there were a lot of attorneys, therefore, we didn't speak up. There are just some things--I think there's a big class difference between the secretaries and attorneys and paralegals. A big class difference. That gets to you sometimes. They put their pants on the same way other people do. They're no better or different. I think sometimes, they're really busy and their focus is elsewhere. They don't mean to act like that sometimes. For the most part, though, I get along with the attorneys.
\end{abstract}

Concern arising from class difference between attorneys and legal staff are not uncommon for law firms, especially within larger firms. Furthermore, the condition of knowledge-orientated work along with inter-colleague discourse creates a certain interdependency among individuals of such professions (Lazega 2001: 16). The same can occur within the legal staff because of similar work conditions and occupational experience. However, the analysis has thus far demonstrated a cultural difference in the relative formality of such relations. The cultural interaction between $\mathrm{ABC}$ Law and XYZ Law during the earlier stages of the merger verified such an organizational emphasis on distinction.

\title{
Attorneys
}

The employees of the newly merged firm possessed utmost respect for the attorneys at the Stonebridge Office. Competence, as a core component of attorney 
professionalism, was strongly viewed as being an attribute worthy of gaining employee respect. Respect towards attorneys was an outward reciprocation of professional conduct.

On a professional level, employees feel a sense of admiration for the attorneys. Secretary Annie Weissbecker noted:

These individuals that we work with were top in their class at their law schools. So you have to respect them for their intelligence, whether you like them or not. They're good at what they do.

Contrary to the previous section related to hierarchy, attorneys receive the respect of their subordinate employees through their hard work and intellect. Although a range of personalities exists within a given organization, the administrative staff at the Stonebridge Office were impressed by the conduct of their own attorneys. The tenacity of their work ethic and scope of their knowledge were two often cited elements commanding the respect of A-Z Law's administrative staff.

Other parameters for generating respect emerged in comments offered by the employees of A-Z Law. One such quality was a display of gratitude upon the completion of a task. A-Z Law employee Glenn Baker saw such an exhibition quite positively:

I've kind of got close to a majority of the attorneys. I feel like most of them have a very open mind to the work techniques I'm interested in, so I'll try to implement them into our system. I think they are very encouraging, and for the most part, they are very appreciative. They'll tell you "thank you". You have some that want to be bigger than life, but for the most part they'll say thank you. They'll send you an e-mail. That's another good thing. When you do something good, it's doing my job--they'll send e-mails to other people. For the most part, I enjoy working with the attorneys.

Although a portion of the previous passage indicated a sense of annoyance with the class conscious attitude of attorneys, Mr. Baker felt that the attorneys at A-Z Law were sincere. 
The extent of legal knowledge possessed by the firm was widely recognized

the moment the merger took place. As marketing efforts, internal literature, and the impressions of employees indicated, the larger pool of legal talent at A-Z Law was first rate and a sign of increased stature. On a peer level, attorney Chris Tennant felt completely content with the type of attorneys at A-Z Law and gained a sense of collegial solidarity:

I am very proud and happy with literally every attorney that I've had the pleasure of working with in our firm. I really don't think there is any lawyer I wouldn't work with nor would I not encourage to have as their attorney to work for. I talk from an internal perspective, I guess. I couldn't be happier with the other attorneys at A-Z Law. I get along with them professionally and personally.

As the narrative indicates, attorney competence is an organizational characteristic realized by administrative employees and attorneys alike. Although many administrative employees felt conscious of a strict legal/non-legal hierarchy, a deep rooted respect for the attorneys was equally palpable.

\section{Administrative Staff}

The value of competence was a reciprocal attribute between attorneys and administrative staff. As a vital component of the modern law firm, attorneys concurred that the administrative staff at A-Z Law was a competent workforce capable of handling demanding tasks. As a requisite for attaining entry to such a position, dexterity to meet demands was a key element in the production of quality work. Qualified administrative personnel are integral to quickly process the knowledge of attorneys into work product. Without the existence of such an ethic attentive to quality, attorneys would risk a deleterious effect on their legal practice. Therefore, a shared respect through the ideal of competence between attorneys and 
administrative staff was vital to the transformation of legal knowledge into a refined product.

Large law firms possess a large non-legal staff involved in the more repetitive aspects of legal practice. Secretarial positions require a college education and moderate knowledge of computers. Clerical work at A-Z Law was done by a pool of college educated and experienced secretaries. Attorney Pamela Wolczak understood the importance of a large, qualified administrative staff, as her previous law firm had not possessed such a vital component of legal practice:

I think they do a great job. I do think there's always going to be some 'weeding out'. They are very good to work with. I think they're a great staff to work with and I am very appreciative of them. We didn't have a staff at EquiLaw. You did a lot yourself. It is very beneficial to have such a staff.

The appreciation of the support staff was widespread among the attorneys due to the understanding that such work is difficult. In addition, this division of labor prevents attorneys from being mired by administrative tasks. Although visibly hierarchical in their relationships with attorneys, the support staff received a deep admiration from the attorneys.

Qualifications and training for the secretary position were a concern for secretaries at A-Z Law, thus exhibiting an ethic of personal excellence at A-Z Law. Shortcomings to this standard were noticed at the "floater" position. As a migratory occupational position, floaters received work assignments either due to an overflow of work or absence by full-time secretaries. Basic clerical support was the required occupational capacity of this position. In the bureaucratic scheme of the law firm, floaters occupy a temporary gap within work groups. Although structurally designed to continue the production of legal work, floaters often possess 
shortcomings in qualification, which resonated in the minds of secretaries with more orthodox work arrangements. Such basic qualifications were scrutinized by fulltime secretaries. Maureen Yates indicated such a phenomenon:

What I don't like is the fact that sometimes they don't hire someone qualified. And that happens occasionally at the floater position. At this moment, I don't know if they were so hard up to find a warm body for the position. You might as well not have anyone at all. Say you're gone for a day or something, you need someone qualified to perform basic legal secretarial skills. I think they're lacking in that when they hire the floater's position. Other than that, I think everybody's great. You've got that many women, that many personalities, but you're in a pinch they all come together.

According to Ms. Yates, the continuation of secretarial support in the case of a secretary taking vacation or sick days was quite a significant problem. With the norms of excellence and competence prevalent at A-Z Law, underqualified personnel became obvious. As a function of industry demands, the fast-paced environment of A-Z Law required adequate training at the secretarial position, even for floaters

The concept of work overflow was another emerging theme within the comments from administrative staff. As subordinates in a bureaucratic organization, secretaries usually remain connected to assigned work groups. However, as Ms. Yates described towards the end of her narrative, secretaries consolidate their efforts whenever collective demands override hierarchical positions. Therefore, organizational flexibility occurred as the uncontrolled rate of work trickled from attorneys to secretaries. Unlike manufacturing settings where product output is measured and closely monitored, the production of legal services does not remain static. Flexibility is important in work flows due to the nature of legal practice and variable client relationships (Lazega 2001: 79). Although some work groups follow 
a more strict bureaucratic model, teamwork for the collective interests of the firm was noted by paralegal Rose McMullen:

They're really willing to pitch in, even when it's [the task] not in their job title. On the whole, everyone is willing to do whatever it takes, regardless of who's coin it is. There are some exceptions to that, but for the most part it's like "you need to get something done, what can I do to help?"

Flexible work routines to achieve the welfare of the collective whole rather than remaining in fixed bureaucratic positions was a departure from the more formalized work arrangements within A-Z Law. This flexibility due to work overflow was in direct contrast to maintaining specific job descriptions and work groups. Flexibility in work arrangements exhibited more of a cultural ethic of camaraderie than the need for static work groups. However, the secretarial staff spends most of its time within formally arranged networks.

\section{Paralegals}

As an occupational class, paralegals exist on the legal/non-legal hierarchical divide. Their tasks vary from knowledge-based activities to administrative functions. Paralegals are qualified through their training to draft legal documents and conduct legal research per the request of attorneys. They also engage in administrative tasks such as organizing documents that are important for attorneys during trial. Some paralegals are responsible for maintaining office financial records. The use of paralegals is also a relatively new enterprise within the profession (Bishop 2002: 11). Themes relating to this group of paraprofessionals varied in either receiving complete respect or contempt with regard to competence.

A consistent view of paralegals was absent. Whereas the previous analysis of relationships between attorneys and administrative staff exhibited a reciprocal 
sense of respect, work ethic and distinctive division of labor, paralegals were seen

as integral but, at times, unproductive to the firm's operation. As employee Bryce

Campbell stated:

I think the paralegals are overworked at A-Z Law. From what I have gathered through speaking with paralegals and paralegal clerks, they have a pretty large workload. I think because attorneys bill at such a high rate that they're handing work to paralegals to bill at a lower rate for clients. They do that and are relied upon on a lot of things they are not experienced with or have the time to do. I think they're a well-trained staff.

Attorney Chris Tennant expressed similar sentiment in regards to paralegals. He felt paralegals were "very capable and very responsive" when they are given the proper information.

Paralegals were regarded with equal disapproval since a divergent subculture existed among the individuals of this occupation. Partner Walt Orton felt that some paralegals "get by and do the minimum." Other employees, such as secretary Janine Rogowski, saw a disparity in the workloads of paralegals. By occupation paralegals exist in a transitory relationship between legal and non-legal tasks. Therefore, paralegals were devoid of a fixed status and occupy a contradictory status within the law firm's formal hierarchy. Ms. Rogowski noticed:

Some of them are okay and some of them I have reservations about. I think some of them feel they are faring better than anybody else, when we all put on our pants the same way. Some of them waste too much time on the phone or on the internet. They have their offices so they can close the door. You know, you come in at work at eight o'clock and sit on the phone until five after nine, to me that's not the right thing to do. It's cheating the company. And we do have some that do that, and I don't think that's right. I don't feel they should expect to do something like that. I feel like some of them will not do their menial things, they'll want to push it off on secretaries. Just because they have a secretary, they don't know how to utilize them.

Ms. Rogowski viewed paralegals with disdain as a result of paralegals' departure from the firm's collective value of hard work. Work group sub-cultures based on external pressures and internal dynamics influence such an inconsistency with mainstream firm culture (Schein 1985: 12). Because the firm grew exponentially, 
regulatory issues emerged. Furthermore, paralegals were work group specific and many members of this occupational category remained within their direct work groups. Group specific paralegals are those employees that rarely stray from static work arrangements. Other paralegals engage in work for a number of attorneys in different practice groups. 


\section{Employee Impressions of A-Z Law's Policies and Practices}

The implementation of uniform policies for the Stonebridge Office to provide a stable structure was imperative, especially during the advent of a threeway integration. As stated earlier, the exponential growth of the firm led to a perceived and actual need for regulatory functions. This section will illustrate how the employees of the new law firm regard formal policies and practices.

\section{Administrative Policy}

Organizational policy had changed due to the structural enlargement of the firm. Employees perceived difference, irrespective of pre-merger affiliation.

Presented as a merger of equals, many aspects of the new firm's operation were presumably negotiated at the top level of management. Within other areas of administration, some pre-merger policies were chosen over the previous models. As employee Bryce Campbell stated:

The ABC Law office came in and were almost forced to adapt to new procedures. $A B C$ Law changed a lot more than $\mathrm{XYZ}$ administrative policies. We've adapted to almost all the policies that XYZ Law had.

He then continued:

Over time, it turned out that a lot of the procedures used in the service center were from XYZ Law, because that is what we were used to. I mean that with surprise. We kept XYZ Law materials because that's what we had. We threw away all of ABC Law's things. That's the way it worked out. Over time, everyone's changed. There's little talk about how things are bad now.

From Mr. Campbell's standpoint, XYZ Law administrative policy appeared more desirable to implement because of the status quo. Indeed, with a larger share of employees, adaptation was presumably less arduous and required less retraining on a firm-wide basis. 
Technological integration was another area of policy that emerged from the comments of A-Z Law employees. As a knowledge-based organization, A-Z Law was required to implement uniform technology throughout its operation. However, EquiLaw remained autonomous through their use of technology, thus revealing a propensity to maintain the status quo within A-Z Law. For ABC Law employees, the change in document management technology did not lead to increased difficulties in adaptation. The new system adopted by A-Z Law appeared similar to the technology used by employees at ABC Law. As employee Samantha Stover indicated:

I remember XYZ Law had to switch to our document managing system. There was a big commotion and nobody liked it. Then we had to change to a new system, but it was very similar to ABC's system. The ABC Law people had no problems picking up on it while the XYZ people did. They had a lot of complaints about it. We had to have joint classes with them.

Ms. Stover's comments were interesting from the standpoint of dominant cultures. In the process of adopting a new system of technology, XYZ employees felt an increased burden to adapt to a new policy. However, ABC Law personnel adapted well since they were more familiar with the new technology. More interestingly, the status quo had a direct influence on the level of adaptation to policies. Although a combination of approaches to policy may increase the impression of a democratic orientation among the employees in relation to the merger, adaptation to XYZ Law policies already in place involved far less personnel. With such a majority of XYZ Law employees within the new firm's population, entirely new policies and subsequent retraining would invariably cause increased disruption to the firm's operation. 


\section{Human Resource Practices}

The role of human resources within the Stonebridge Office was regarded as a very difficult endeavor, especially when clarifying and reinforcing company policies of the integrated law firm. Because of its emphasis on structural control, A-Z Law required positions of active personnel management. However, firm policy possessed some shortcomings in the minds of A-Z Law employees.

A small core of management overlooking a large staff was viewed with both sympathy and scrutiny. Sympathetic to the plight of human resource administrators was secretary Wilma Dahl:

Well, we've had a kind of rocky situation in there with the administrative staff. I actually had a personal situation with someone who is no longer here. And I'm glad she's gone because she wasn't good for the place. Janice Holden [HR Manager], I really like her a lot. I think she does the best she can do and coordinates things. I think she may have bit off a little more than she can chew. I think she's really adjusted well and has done a good job. All the bitching and moaning she hears on a daily basis...I wouldn't want her job.

Administration of the new law firm was regarded as a very difficult, yet necessary endeavor. The new firm's emphasis on structure, which was a vestige of XYZ Law, requires such positions of consistent reinforcement to meet the firm's economic needs.

Although human resource personnel were observed as necessary, the turbulent nature of this activity to respond to administrative issues was discussed in detail. As secretary Maureen Yates responded, her concern was in relation to human resources jurisdiction and attorney authority:

The only thing we need to work on is human resources. The hiring, qualifications of people they hired, that's one thing. They need to do more to react to people's complaints and concerns. I feel that if a concern is against a partner, they are less likely to do anything, unless there are a lot of complaints. Maybe there's a reason for this. I don't know. Maybe that's how they do it. Not just on a certain person's whim or a bad day. But they need to not be afraid to approach the attorney or someone else. 
The need for adequate control and reinforcement was repeated as secretary Janine Rogowski described:

But I don't think they follow through., they don't want to hit things head on. If you come in--and I'm probably off on a tangent--if you come in late or take a long lunch hour or if you're off consistently, you don't punish the entire group for that individual's lack of consideration. You go to that individual and you approach that individual and say "here's a verbal warning and let's get your act together here." You don't take away from the group, people who are misusing, don't take away from them because of an individual.

Firm standards addressed to entire groups were deemed unfair if these standards were intended to solve an individual problem. The previous passage indicated a dynamism to the role of human resources: this position requires a strong active responsibility to enforcing firm policy, yet must remain even-handed when sanctioning individuals over the group. The structural method of authority found within A-Z Law required a strong human resources role in reinforcing standards. However, employees perceived that there should be a limit to the amount of oversight enacted towards the larger group when only individual sanctions were necessary.

\section{System of Rewards}

At every level, A-Z Law employees enjoy competitive compensation and benefits. Employees regarded these areas of firm policy to be well reflective of the firm's high performance standard. Furthermore, employees felt justly compensated for their efforts on a day-to-day basis. Employees felt well-respected in regards to the amount of compensation provided by the new firm. However, the system of bonuses and advancement became areas of contention.

Beyond compensation the new firm implements a system of bonuses and advancement, thus supplementing the firm's legitimacy over normative order. 
comparing them to the standard applicable to attorneys:

I have concerns that they don't have... not mandated, but a formula for raises and bonuses like they do for attorneys. It's strange because I didn't make my billable requirement for last year and I still got a bonus. But if I were an attorney and I didn't make my billable requirement, there's no bonus. But the year prior to that, I billed four hundred hours over, my bonus was the same as someone that just met their billable hours. That's one of my concerns. I think they're doing okay.

The above passage indicated a lack of consistency in bonuses, yet Ms. McMullen felt such an issue to be insignificant. From a secretarial standpoint, Wilma Dahl also reviewed such a dynamic with bonuses:

I think it just seems like a typical business where we're reviewed and make goals. It seems like the typical kind of business the way it's been run. It seems like there's not incentive to bust your ass. No matter if your performance is great or your performance is weak, the raise is about the same. I'd like to see maybe more incentive or being at work and not using sick days and not taking advantage of the system. It'd be nice to get some perks for people like that. people that show longevity. It just is run basically like any place I've ever worked as far as performance.

Although the cultural norms of A-Z Law require a commitment to hard work and competence, systematic rewards for such qualities appeared standard in the minds of employees.

At the attorney level, the policy of promotion emerged as an issue resulting directly from the merger. Associate attorneys, as stated earlier in the literature review, rely on several years of experience and collaboration with more experienced attorneys to achieve the ultimate goal of partnership. To earn such a distinction, many years of dedicated practice to hone their legal talent must pass before such consideration. In many law firms, this "up or out" dynamic leads to considerable stress for associate attorneys. The parameters of evaluation changed unfavorably after the merger, according to experienced associate Chris Tennant. The changed tenure for attaining this goal led Mr. Tennant into a very colorful dialogue: 
I do not think that it was fair for the policy makers to change the rules on individuals that are vested in one particular system, whether it was XYZ Law's system or ABC Law's system. Changing the rules in the middle of the game was a poor decision and I don't know what they're going to gain by it. I know they lost some lawyers as a result of it, but I don't know whether the loss of those lawyers was a function of something else in combination with that, or even if a loss of those lawyers ultimately resulted in greater efficiency and profits for the law firm. I don't know, but my impression is that some of the associates that were lost were lost because of disloyalty or betrayal. Betrayal is a little strong, but at least a callous attitude towards the changing of rules.

For associates, the Cravath System for attaining advancement within law firms is an ever-present issue. Although appropriately compensated, Mr. Tennant revealed a sense of being betrayed by the firm's modification of the associate advancement rules. However, such a changing of rules may benefit the firm in relation to profitability, commonly known in law firms as leverage. Partner to associate ratios are a key component in establishing such a condition (Gilson and Mnookin 1989: 585). At an individual level, though, Mr. Tennant revealed the inherent burden of associates within the Cravath System. The merger's effect on the associate advancement policy increased this burden. 


\section{Emplovee Impressions of the Merger}

All employees spoke of the inherent difficulties encountered within the organization before and after the merger. Job security and organizational direction became concerns for employees. The employees at the Stonebridge Office spoke of two sides to the merger experience: the benefits and drawbacks they perceived are issues discussed in previous research. This analysis was divided into occupational class, thus providing each class' unique view of the merger. Within each occupational category, impressions are further refined into before and after experiences with the merger.

\section{$\underline{\text { Attorneys }}$}

\section{Before}

Some attorneys received advanced warning of a potential merger long before any form of announcement took place. Careful consideration to the similarity of practice area and alignment of firm cultures occurred throughout the negotiation process. However, with organizational change occurring on such a magnitude, attorneys took notice of the possibility of difficulties inherent to such a business activity.

During the consultation phase of the merger, Walt Orton grew optimistic about such a combination of organizational forces, especially after XYZ Law's commitment to proceed with caution:

I don't think I had any negative feeling. I knew some of the partners over there. I think anybody-I'm fifty-eight--any time you have change you don't know whether it's going to affect you positively or not. Probably in our first look I thought why not keep the status quo? But then they started explaining how you could help each other out. They had all these statistics showing the larger you get, the better your bottom line is. You cut the overhead and duplication and that type of thing. It's proven to be a good situation. We didn't know if it would or not, but it has been. 
Initially, you think "why go through all that?" It cost a lot of money to do it for all the outof-pocket expenses for consultant and time by the partners and management by both sides.

Attorney Chris Tennant felt somewhat distressed since he thought the offices were

not compatible. However, job security was not an issue of concern:

My initial feelings were apprehensive. I was pretty steady and comfortable with the position I was in with XYZ Law. I was very confident that my job description and my tasks on a daily basis would not change substantially. So I really wasn't worried about losing my job or being pushed down or pushed out by any lateral peers in the merger. There was some apprehension because I wasn't sure about the compatibility of the office in Stonebridge, which is the only city where the two offices from two separate entities literally came together. So there was some apprehension about that.

From the more individualistic environment of EquiLaw, Pamela Wolczak appeared thoroughly delighted by the prospect of joining such an exciting endeavor:

I was very excited about the whole thing. I thought it was great for us. I thought it was great. I knew more about XYZ Law than ABC Law just because I had worked with them more. I really didn't know anybody except on a professional capacity. I was very encouraged and thought it was a great move for everyone, from my point of view.

Ms. Wolczak believed her individual practice would improve by being exposed to other areas of law complementary to her own specialization. With such an integration of legal talent and a variety of specializations, her practice of law would expand into areas previously unavailable at EquiLaw.

Attorney impressions of the merger did not reveal great feelings of individual uncertainty. However, they did express general concerns about the unknown. Job security, benefits, and other individualistic interests were not mentioned, possibly due to the relative stability of the legal profession and strong demand for lawyers in society today.

After

Attorneys felt a certain degree of success after the merger. The enlargement of legal practice and a wider available pool of legal talent were disclosed as benefits 
of the merger. However, they perceived some shortcomings related to worker

turnover. Walt Orton stated overall success, but with a price:

I think it's been successful. I think there's been a lot of folks that left. They just didn't like that kind of setup. We've lost thirty employees out of four hundred because of personalities. They didn't like the situation and it just didn't work out for them. I think it's doing okay. I think it's been alright.

The loss of employees was perceived differently by Pamela Wolczak, as a majority of EquiLaw's employees departed the firm after the merger. As Ms. Wolczak revealed, her impression of the merger was greatly influenced by this loss:

I think that I am a little tainted because of coming in with EquiLaw and the EquiLaw people leaving. It puts me in a unique situation as to being on a ship without a sail. I am really at a loss for what I am... for what role I am going to play. But I do see, I see a lot of personalities and I am sure this is the way for a lot of mergers. I don't see one leader coming to the forefront. I don't see a cohesion that is required to be successful. I don't see an agreed upon structure or agreed upon anything within the firm.

The amount of change experienced by Ms. Wolczak was rare in comparison to the employees of the other merging firms. Her impression of the merger was greatly influenced by the departure of her colleagues, which left her in a confusing situation within a larger law firm. Interestingly, her view of a lack of singular leadership appeared a function of her previous firm experience, as EquiLaw was a firm with an identifiable, charismatic partner.

Additional legal resources allocated after the merger were vital for fulfilling the needs of clients. Although suffering from the loss of former co-workers, Pamela Wolczak found value in the large amount of diverse legal talent:

Having people in every field. There are some people I go to Flower Mountain for, some in Redland Heights, some in Yellow Springs. To me that's a huge benefit. That should be something people should be aware of. Because the sum of the whole is greater than its parts.

Chris Tennant added:

I think one of the most significant aspects of the merger is that we've bcen able to associate ourselves with some very exceptional attorneys in Redland Heights who have experience that our attorneys in Stonebridge do not have. The [withheld] department in Redland 
Heights as well as the [withheld] practice in Redland Heights has brought elements to the firm that XYZ Law didn't have, and it's a very positive thing for the new organization and our clients. It think that's the biggest positive that I can articulate.

The combination of legal talent within the new firm was momentous, according to the attorneys. In the spirit of collegial organization, the addition of more professional perspectives leads to an improved work product.

\title{
$\underline{\text { Secretaries }}$
}

\section{Before}

Secretaries with previous merger experience viewed this merger with skepticism. Consistent with the literature, uncertainty about the potential for change was a recurring issue for employees experiencing such organizational change. This uncertainty usually involved job security, benefits, and other individual interests.

Secretary Wilma Dahl recalled her previous experience with mergers:

\begin{abstract}
Well, the people get really nervous and it comes down to how it will affect me. Until you see that in black and white, you feel uncomfortable. You don't feel secure where your job's going and then you start thinking, "Should I go look for another job? Should I have a backup in case this doesn't fly? Because who knows? Maybe they won't need me. We felt bad at ABC Law. You start hearing numbers and how many secretaries they need for how many attorneys. And then you start thinking, "It sounds like they have enough secretaries, maybe I'll be let go." Just the uncertainty of your future when you hear the word 'merger', then you think about downsizing. Those kinds of things that go along with it. Even though you say 'merge' sometimes that means fewer people.
\end{abstract}

Janine Rogowski added that fringe benefits were a concern due to a foreseeable

downturn. This drawback related to mergers derived directly from her own previous experience with such a business activity. Unlike attorneys, secretaries typically do not establish their own professional practice. The recurring impression of the merger among secretaries involved these fundamental aspects of their employment, rather than concerns about the operation of the firm. 


\section{After}

Although primarily concerned with fringe benefits as the prospect of the merger unfolded, some secretaries felt more secure with their position while others anticipated a slight change to their benefits. However, the amount of change did not coincide with their guarded pre-merger impressions. Wilma Dahl felt relieved after the integration of the smaller ABC Law office:

It's much more positive than the first month after we officially merged. I feel like I am relaxed a bit. I fit in now and I realized they were doing everything they could to make us more comfortable. I like being a part of a large firm. I feel somewhat secure. Maybe that's a bad word to use. But it's okay for me.

Secretary Janine Rogowski saw no advantage of the merger other than the increase in firm size. The only change related to a slight modification of fringe benefits.

This theme was also highlighted by Gwen Ribbendorf, whose impression of the merger was mixed:

I think we're, as far as me as a legal secretary, really the only thing that changed was our fringe benefits got cut. It really didn't do anything positive for us. If anything, what it did was negative. I didn't see anything positive coming out of it for the legal secretaries, paralegals or any administration jobs. I don't know about the attorneys, but it really hasn't affected my job. Just the benefits.

The main theme emerging from secretaries involved fringe benefits and their cautious view of the merger's advantageous aspects. Although secretaries felt an obvious change in the firm's productive capacity and size, the advantages of the merger were perceived as being very limited.

\section{Paralegals}

\section{Before}

From a contradictory occupational position located between the legal/nonlegal distinction, paralegals divulged impressions of enhanced organizational 
capabilities. Common to their view was the solidification of firm reputation based

on size. As Rose McMullen stated:

I thought it was great. I thought it was gong to be a great thing. It's going to make it a larger firm. The largest firm between [city name withheld] and [city name withheld]. I thought it was pretty great. I thought it was pretty great that you could work for a company because of it.

As a paralegal of the smaller $\mathrm{ABC}$ Law firm, Linda Jones became concerned about layoffs. However, this view changed as the integration phase of the merger came to an end.

\section{After}

Paralegals felt satisfied with the work environment after the merger integration. Increased amounts of firm resources and general relief were themes within the discourse. As Linda Jones said:

Well, I have a job. That's positive. I think it's good for the firm. They can say they have offices in several states instead of a few. [We have] knowledge, experience. They pass a lot of stuff inside and keep it in-house. As for the employees, I can't see a difference between unmerged and merged--it's about the same.

Assimilation was a key element in the previous passage, as Ms. Jones sensed uniformity within A-Z Law. Rose McMullen acknowledged a period of employee turnover, but felt a greater good accomplished by the merger:

Now that we lost those people. I think we have, the XYZ Law people had different groups that did things that we didn't have that did those kinds of things. Like we didn't have a [type of practice withheld] group. It's great to be able to go through...to have resources for your client and say "we can start to do this, and we have these guys in Redland Heights or Flower Mountain." That's the biggest thing. We have more experience.

After spending some time to integrate offices, these employees began to feel more comfortable with the stability of their organization.

\section{Other Employees}

Employees within this occupational grouping--which includes marketing personnel, office service coordinators, runners, receptionists, and kitchen workers-- 
approached the merger with feelings of impending change. For some, the lure of a lucrative corporate setting created a strong sense of opportunity. This was well illustrated by employee Glenn Baker, who felt the merger coincided with his personal goals:

Personally, I welcomed it. I'm about change. Taking risks, especially when it's going to make things happen. Like I said, when the attorney spoke with me about staying, it was not only the firm that was progressing, but also myself. I was looking forward to it, to see exactly what it was about. I always read about technology a lot. I'm always reading magazines about mergers, businesses taking over, and it was interesting to go through something like that.

Although the above passage exhibits an adventurous sense of opportunity in a larger setting, other employees regarded the merger as an altogether different activity. As employee Bryce Campbell analyzed the prospect of a merger, he perceived his company's greater influence over the entire process:

There was talk of maybe two offices in Stonebridge coming together. I wasn't too familiar with the whole merger situation. I didn't know that people we were merging with were located in Redland Heights and Flower Mountain. Basically a merger of equals between the two. But nobody mentioned that. Everyone kind of--rumors were going around in the office. Apparently, we were taking over another office. That was the rumor at XYZ Law, that we were 'taking over' another office, which may in turn have upset people when they found it since we were supposed to have a merger of equals as opposed to what the rumor was: we're taking over the office.

The feeling of takeover enveloped employee Samantha Stover of ABC Law. As with many secretaries of each pre-merger firm, Ms. Stover's apprehension was rooted in possible ramifications to fringe benefits and job security.
After
From a business standpoint, the merger was viewed with opportunism by employees who were not attorneys, paralegals or secretaries. However, these employees experienced a difficult stage of integration that was overcome. The following interview quote is similar to earlier passages offered by paralegals, 
secretaries and attorneys. Once cultural and structural differences were resolved,

the merger was regarded as a good venture. As Bryce Campbell indicated:

Overall, one more time, as of today I think it's been good for me. They've expanded so much that Stonebridge is a large office now. We got new departments--we have a marketing department that we never had before. I think they're working out well. The Marketing Staff in Stonebridge is really helpful in anything we need to do. We help them out. It's starting to become a little better. Firm morale is going up. At times, the ABC Law people didn't want to get along with the XYZ Law people. They saw themselves as different, it was almost like segregation at the time. But it's grown to where we've all started working together.

As various employees stated in previous narratives, the merger was a difficult process to endure and an experience which was integral to the current development of the firm. Glenn Baker observed the benefit of the enterprise and stability for the future:

From a business standpoint, it was an excellent idea. Both sides have really benefited. After two and a half to three years after the merger, it has really come together. At first, different philosophies and different ways people did things on a day-to-day basis conflicted. You could tell. People weren't hiding that. I think there's an even flow. Here and there we run into some things just because there's a lot of things on the surface. The things underneath, you don't have to deal with until they come up. Some of those issues have come up recently. Like I said, from a business standpoint it was great. From a relationship standpoint, I think it took its toll with a lot of employees having to change.

Employees in this occupational class saw the merger mostly as a positive experience when regarding the future, but also one which provided acute workplace difficulties. This group of employees often talked about cultural differences and subsequent conflict. This further confirms the presence of varying derivative workplace cultures within the integrated firm and the outcomes of such contingencies. 


\section{Work Routine Change within the Integrated Workplace}

Work routines change for various members of merging organizations.

However, no systematic pattern of change in work routines is common to the law firm under study, especially when regarding this change in reference to different hierarchical positions. The influence of turnover, layoffs, structural enlargement, and seniority practices all have the potential to alter work routines. Interestingly, the employees indicating a change in their work routines are all those directly affected by structural change, especially employees of the smaller pre-merger firms.

\section{Structural Expansion Creating New Occupational Tasks}

When organizations expand in size and scope, new occupational positions are created. Bryce Campbell explained that his work routines changed considerably after the merger:

\footnotetext{
My duties have changed dramatically, as a matter of fact. Along with the duties I was doing before, there are a lot more people, so my job load has increased. The actual job description has changed to where it's a larger workload and we've incorporated two systems into one. In the process of doing so, we've had to change and have a new job description and procedure in place.
}

As the quote indicates, the structural expansion after the merger created an entire array of new tasks. An increase in the size of overall staff coupled with work intensification produced greater needs for social organization. Formalization of these social arrangements was completed through modifications in job titles and tasks to accommodate this structural change. Furthermore, as an integral component of the modern law firm, the support staff came into creation as law firms increased in size and sophistication. Mr. Campbell's experience demonstrates the further development of the law firm through expanding its non-legal personnel base into more specialized work units. 


\section{New Positions}

Employee Glenn Baker indicated a similar outcome of structural expansion of the merged law firm. As an employee of ABC Law, the merger with XYZ Law appeared lucrative for an entirely new and exciting position:

It just so happened that with the merger, with our offices becoming larger, we were able to create the job for it. We were able to start a new department in Stonebridge, which they already had in other offices.

With the advent of the merger, the size of the office in Stonebridge nearly doubled and its development mimicked that of larger offices within the company's branch office structure. Specialized departments functioning to fulfill certain organizational needs was also reminiscent of the growing law firm. The new department referred to in the quote above, and more specifically Glen Baker's position, developed through a lengthy process:

Yeah, pretty much as soon as they merged, this aspect became available. So, I slowly progressed into it, but I did not have the full aspect of what I do now. Basically, it is putting material together, just kind of assessing the overall needs for attorneys. Then, as I got more accustomed to what we did and what the other offices did and what my goals were, I walked into the role I have now.

Inferred from the previous account is the emergence of new occupational duties through a negotiation process between Stonebridge and its more developed offices. Through it's distinctive economic setting and rigid, standardized departmental procedure, a job title and its corresponding work routine never previously known in Stonebridge came to the fore.

\section{Changing Work Routines for Individuals of the Smaller Firms}

Non-legal staff members of $\mathrm{ABC}$ Law, the explicitly equal yet smaller merging partner of XYZ Law, experienced a dynamic change in their work routine as a result of the merger. The change encompassed two different occupational 
positions of the firm's non-legal workforce. Linda Jones, a paralegal of $\mathrm{ABC}$, reveals an additional dimension in this type of change with her unique involvement with the third merging party, EquiLaw. As a temporary measure, $\mathrm{ABC}$ Law and this smaller organization were integrated until adequate office space allocation took place to accommodate all three firms. The work routine included interaction with several employees of EquiLaw. As a part of a temporarily integrated workforce between $\mathrm{ABC}$ Law and EquiLaw, Ms. Jones worked with EquiLaw employees accustomed to different work procedures. As stated earlier, ABC Law and EquiLaw existed as an integrated workforce to fulfill lease obligations. The modification in work routine was also a temporary measure.
Well, at first it was tough. There was a transition period. Even though I was an ABC Law employee, I came in with the EquiLaw group. At that point I was doing other tasks. So I was dealing with two mergers. That was difficult. After I left that group and got into a regular work group... I reckon at that point it was A-Z Law, then it was good.

As demonstrated by Ms. Jones' statement, an initial integration of the two smaller offices (ABC Law and EquiLaw) modified work routines for this paralegal. Moreover, the merger generated a wider practice of law, leading to even more possibilities of paralegal involvement in areas previously removed from their normal work routines. Although such change may lead to more depth in individual work experience, the difficulty encountered during a merger is quite apparent.

Another illustration of work routine change was the case of Wilma Dahl, a secretary of $\mathrm{ABC}$ Law. The change in work routine developed from turnover of former $\mathrm{ABC}$ Law attorneys and administrative decision making. To fulfill the staffing needs of the firm, Ms. Dahl encountered a different work routine, one previously unmatched at $\mathrm{ABC}$ Law: 
They did add someone and for awhile it was really bad, to the point of... it was very unfair to me the person they gave me, knowing the workload she has too. Since then, that's been adjusted. It's more of a balance for me.

Organizational flexibility is a key element in the above passage. While work routines change and difficulty persists, the organization's functional aspects become increasingly tested. Both of these accounts indicate a certain level of organizational flexibility of the new firm to manage work routine change for the reestablishment of stasis. 


\section{CHAPTER V}

\section{Conclusion}

The results of this study have demonstrated the situation employees encountered during the advent of a three-way merger. Organizations derive cultural and structural attributes as a direct response to external pressures and internal dynamics among employees. Each pre-merger firm possessed varying structural and cultural configurations as indicated through the impressions of employees of each firm. These three firms with unique histories integrated to form a single organization. Office size, employee composition, and memories of past routines influenced employee views of the new organization.

The study also portrayed the phenomenon of enduring cultures, as in the case of XYZ Law in relation to the new incarnation of the firm. Employees of XYZ Law saw little apparent change in their work environment, social arrangements, and office dynamics. However, the employees of both ABC Law and EquiLaw perceived an altogether different picture. Their narratives provided a glimpse into the experience of employees adapting to great organizational change, the difficulties of overcoming such change, and the eventual merger integration at the time of the interviews. Furthermore, the amount of change perceived by employees derived from a realization of XYZ Law's bureaucracy and stronger adherence to formal social relations, which were noticeable deviations from their pre-merger 
organizations. The developed organizational structure of XYZ Law made a leading contribution to the future structural and cultural form of the new organization. Given the adaptation to change and attractiveness of growth within the legal services industry, both the ABC Law and EquiLaw offices in Stonebridge would develop into more complex organizational entities, with greater emphasis on the administrative functions of economic operation. However, the magnitude of organizational change inherent to a merger transplanted these smaller firms into a more bureaucratic environment in an instant.

Another area of the research covered the topic of organizational policy. Several administrative policies from XYZ Law remained intact within the new law firm. However, all employees felt the impact of new policies created as the firm expanded. Although the cultural and structural influence of XYZ Law was demonstrated, new policies emerged. Some of these new policies were criticized, while a need for new policy in other areas of the firm's operation became evident through the employees' perspective.

Impressions of the merger from specific occupational perspectives provided a distinct view into the expectations of the merger. Attorneys viewed the combination of legal talent with great enthusiasm, while members of the administrative staff became fearful of job insecurity because of past experience with mergers. However, as time passed, most of the employees perceived a more harmonious existence within the new law firm. Indeed, many felt an increased awareness of the new firm's stabilizing power. 
The growth of the law firm also led to the creation of new job classifications. The expansion of the law office created a more complex and vibrant environment capable of producing large amounts of quality legal work. As the literature and the research abundantly demonstrated, employee turnover is common during a merger. However, opportunity to attain new employment also emerges. The prospect of attaining new positions was made even more attractive due to the law firm's usually static occupational positions.

Several implications emerge from the conclusion of the research. The first implication is theoretical. Through the grounded theory approach, the themes emerging from the data support Max Weber's compelling theoretical work on bureaucracy. As small organizations grow into large ones, they experience bureaucratization gradually. In a merger of the sort studied here, the small firms experienced sudden bureaucratization, thus magnifying the growing pains. In addition, several aspects of the research also correspond to various post-Weberian orientations, especially in reference to the interrelation between culture and structure. With the completion of this study, a contemporary knowledge-based organization is added as a variant to the ideal-typical bureaucratic scheme originated by Weber. The research contributes one more analysis in the growing theoretical work on organizational typologies.

The second implication relates to the research methodology. Several limitations to the research methodology are conceded. An underrepresentation of partners within the sample limits the scope of the data collected in areas of firm authority and decision-making. Moreover, additional partners participating in the 
research could yield insight on the collegial aspects of legal practice. Another methodological limitation involves the before and after comparisons among XYZ Law employees when contrasting their pre-merger firm to the merged firm. Although the data showed that the culture and structure of XYZ Law greatly influenced the A-Z Law work environment, further examination of the nuances of these differences could provide a more in-depth analysis of firm culture. The final area of methodological limitation involves the employees who left the law firm during the course of the merger. By including this former segment of the firm's population, a greater view of the merger's effect could have been generated. Comparisons between departing employees and those employees remaining at the firm could provide insight upon the reasons for such decision-making.

The final implication involves practical considerations derived from the research. Compatibility of practice areas is one such consideration. Previous literature demonstrates the conflict between economic values and core professional values within the practice of law (Sandefur 2001). Because of the combination of organizations with unique work environments, compatibility is an issue of concern. The research demonstrated that bureaucracy is one such parameter of compatibility. In the case of $\mathrm{ABC}$ Law and EquiLaw, merging within the larger more complex bureaucracy of XYZ Law was extremely difficult. Although the bureaucratic scheme on a firm-wide basis was similar in development between ABC Law and XYZ Law, the Stonebridge Office possessed the more advanced bureaucratic structure of XYZ Law.

Another practical implication involves the adaptation of a more 
professionally independent culture into one emphasizing structure. The acquisition of EquiLaw provided A-Z Law with a specialized area of legal practice complementary to an already established department. However, the professional independence practiced by members of EquiLaw leads to a likelihood for divergence within a larger more bureaucratic setting.

The final area of practical implication involves communication. As both the previous literature and research demonstrate, uncertainty and conflict often accompany a merger (Schweiger and Denisi 1991). Firm-wide communication at critical junctures in the merger process to address concerned employees can alleviate such feelings of uncertainty, especially in regards to job security, fringe benefits, and work routines. In addition, potential disputes over cultural and structural approaches can be alleviated through communication. More specifically, a statement explaining that adopting certain approaches are neither right nor wrong can lead to a greater understanding of the issues surrounding a merger. In the case of XYZ Law's influence over these aspects of the organization, such an outcome is less disruptive to the overall operation of the firm. The fact that XYZ employees comprise most of A-Z Law's population is a great determinant of post-merger influence over procedure. Conversely, retraining the entire office in order to alleviate feelings of cultural inferiority can also be disruptive to the operation of the merged firm. Although conflicts may occur even after addressing such uncertainty, an official communication to the firm's personnel can overshadow the influence of personal assumptions and rumors.

Mergers are an ongoing business activity bearing an impact on the cultural 
and structural foundations of organizations. This particular analysis offers an additional organizational setting to the widening field of research on organizational culture. Although law firms possess some cultural and structural differences when compared to other organizations, sociological concepts are applicable to law firms as well as other organizations. The concepts of bureaucracy, division of labor, hierarchy, normative order, and status refer to the basic social aspects inherent to all organizations; all of which are subject to change during the course of a merger. Further research in other areas of industry is needed to keep pace with merger activity and the inherent social implications that a combination of workforces bear upon the work lives of individual employees and the organization. 


\section{REFERENCES}

Alvesson, Mats and Per Olof Berg. 1992. Corporate Culture and Organizational Symbolism. Walter de Gruyter: Berlin.

Author Unknown. 1993. "Independence is a State of Mind." The Economist. April 10,pg. 67.

Author Unknown. 2000. "The Urge to Merge." The Recorder. July 20, pg. 1.

Babbie, Earl. 1999. The Basics of Social Research. Belmont, CA: Wadsworth.

Berg, Bruce L. 2000. Qualitative Research Methods for the Social Sciences. I Boston: Allyn and Bacon.

Bishop, Lou Don. 2002. "Definition, Regulation, and Licensure of Paralegals in the United States." Dissertation. Virginia Polytechnic Institute and State University. Blacksburg, Virginia.

Browne, Lynn E. and Eric S. Rosengren. 1987. "The Merger Boom." Pp. 17-37 in Proceeding of a Conference Held at Melvin Village, New Hampshire. Federal Reserve Bank of Boston.

Buono, Anthony F. and James L. Bowditch. 1989. The Human Side of Mergers and Acquisitions. San Francisco: Jossey-Bass.

Castells, Manuel. 2000. The Rise of the Network Society, second edition. Oxford, England: Blackwell,

Farganis, James. 1996. Readings in Social Theory: The Classic Tradition to PostModernism. Second Edition. New York: McGraw-Hill

Federal Trade Commission. June 16, 1998, FTC Chairman Robert Pitofsky Discusses Merger Wave in Senate Judiciary Committee Testimony: Globalization, Deregulation, and Technological Changes Cited as Factors in Record Number of Hart-Scott-Rodino Merger Filings. Washington D.C.: Federal Trade Commission Consumer Response Center. 
Federal Trade Commission. April 25, 2001, Prepared Statement of the Federal Trade Commission FTC Merger Enforcement in the Gasoline Industry Presented by Chairman Robert Pitofsky Before The Committee on Commerce, Science, and Transportation Subcommittee on Consumer Affairs, Foreign Commerce, and Tourism United States Senate. Washington D.C.

Fergus, Jean M.H. 2000. World Law Business. London, England.

Fine, Gary Alan. 1984. "Negotiated Order and Organizational Cultures." Annual Review of Sociology. 10:239-62.

Flom, Joseph H. 2000. "Mergers and Acquisitions: The Decade in Review." University of Miami Law Review. 54: 753-781.

Galanter, Mark and Thomas Palay. 1991. Tournament of Lawyers: The Transformation of The Big Law Firm. Chicago: University of Chicago.

Gilson, R. J., and Mnookin, R. H. 1989. "Coming of Age in a Corporate Law Firm: The Economics of Associate Career Patterns." Stanford Law Review, 41: 567-595.

Hamada, Tomoko and Willis E. Sibley. 1994. Anthropological Perspectives on Organizational Culture. New York: University Press of America.

Hodson, Randy. 1999. "Organizational Anomie and Worker Consent." Work and Occupations. 26: 292-323.

Hoffman, Paul. 1982. Lions of the Eighties: The Inside Story of the Powerhouse Law Firms. Garden City, N.Y.: Doubleday.

Hofstede, Geert. 1994. Uncommon Sense about Organizations: Cases, Studies and Field Observations. Thousand Oaks CA: Sage Publications

Hovenkamp, Herbert. 1994. “Antitrust Policy After Chicago." Pp. 157-228 in Evolution Of Antitrust Policy from Johnson to Bush, edited by Robert Himmelberg. New York: Garland Publishing.

Kanter, Rosabeth Moss. 1984. Change Masters. New York: Simon and Schuster.

Katzman, Robert, Marc Galanter and Thomas Palay. 1995. The Law Firm and the PublicGood. Washington D.C.: The Brookings Institution.

Kelly, Michael J. 1994. Lives of Lawyers: Journeys in the Organizations of Practice. Ann Arbor: University of Michigan. 
Kivisto, Peter. 2000. "Social Theory: Roots and Branches." Roxbury Publishing: Los Angeles.

Kole, Stacey R. and Kenneth Lehn. 2000. "Workforce Integration and the Dissipation of Value in Mergers: The Case of U.S. Air's Acquisition of Piedmont Aviation." Pp. 239-85 in Mergers and Productivity, edited by Steven Kaplan. Chicago: University of Chicago.

Lazega, Emmanuel. 2001. The Collegial Phenomenon. Oxford University Press: New York.

Marks, Mitchell Lee. 1999. "Adding Cultural Fit to Your Diligence Checklist." Mergers \& Acquisitions. The Gale Group.

Merriam, Sharan. 2002. Qualitative Research in Practice: Examples for Discussion and Analysis. San Francisco: Jossey-Bass.

Mirvis, Phillip. 2001. "Corporate Culture Clashes Can Harm Mergers and Acquisitions." The Society for Industrial and Organizational Psychology, March 2, pg. 30.

Nahavandi, Afsauch and Ali R. Malekzadeh. 1988. "Acculturation in Mergers and Acquisitions." Academy of Management Review. 13: 79-90.

Probst, T. M. 2003. "Exploring Employee Outcomes of Organizational Restructuring: A Solomon Four-Group Study. Group and Organization Management. 28: 416-439.

Ramu, Shiva S. 1998. Corporate Growth Through Mergers and Acquisitions. London: Sage Publications.

Ravenel, Sean P. 2002. "The Contagion of Example: Attacking the Root of the Problem in Lawyer Professionalism." The Federal Lawyer. 49: 31-44.

Samuelson, S.S. and L.J. Jaffe. 1990. "A Statistical Analysis of Law Firm Profitibility.” Boston University Law Review 17: 185-211.

Sandefur, Rebecca L. 2001. "Work and Honor in the Law: Prestige and the Division of Lawyers' Labor." American Sociological Review. 66: 382-403.

Schein, Edgar. 1985. Organizational Culture and Leadership. Jossey Bass: San Francisco.

Schoenberger, Erica. 1997. The Cultural Crisis of the Firm. Cambridge, MA: Blackwell Publishing. 
Schultz, Majken. 1995. On Studying Organizational Cultures: Diagnosis and Understanding. Berlin: Walter de Gruyter.

Schwieger, David M. and Angelo S. Denisi. 1991. "Communication with Employees Following a Merger: A Longitudinal Field Experiment." Academy of Management Journal. 34: 110-35.

Smirlock, Michael, Randolph Beatty and Saman Majd. 1986. Taxes and Mergers: A Survey. New York: Salomon Brothers Center for the Study of Financial Institutions.

Smith, Kenneth W. 2000. "A Brand-New Culture for the Merged Firm.” Mergers and Acquisitions. 35: 45-53.

Sterans, Linda Brewster and Kenneth D. Allan. 1996. "The Merger Wave of the 1980s." American Sociological Review. 61: 699-718.

Straus, Anselm and Juliet Corbin. 1998. Basics of Qualitative Research. Thousand Oaks, CA: Sage Publications.

United States Senate. June 16, 1998. Testimony of Chairman Alan Greenspan Before The Committee of the Judiciary. 


\section{APPENDIX A}

\section{$\underline{\text { Interview Questions }}$}

Attorneys

1. What is your job title at A-Z Law?

2. Please describe your major job duties.

3. Which company were you employed by before the merger?

4. Have your duties changed since the merger? (If yes, in what ways?)

5. Can you please describe to me in detail your work life before the merger?

6. Can you please describe to me in detail your work life after the merger?

7. How did you hear about the merger?

8. What did your former employer, that is your employer before the merger, do to address the merger?

9. What were your initial feelings about the merger between ABC Law, XYZ Law, and EquiLaw?

10. What are your feelings about the merger now?

11. What was your feeling about working with the employees of the other firms?

12. What specifically did the new firm do to introduce employees from all three firms?

13. What is your impression of A-Z Law's current expectations of their employees?

14. How do you regard pro bono opportunities within the firm?

15. How do you feel about the standards for billable hours? What were the standards before the merger? 
16. How do the firm's demands impact your life outside the firm?

17. How would you define success on a daily basis?

18. How do you feel about the administrative staff at A-Z Law?

19. How do you feel about other attorneys at A-Z Law?

20. How do you feel about the paralegals at A-Z Law?

21. How do you regard your former employer compared to the new firm?

22. What concerns do you have about the new firm's overall operation?

23. What would you regard as being the positive aspects of the merger?

24. What would you regard as being the negative aspects of the merger?

25. Can you please state your gender?

26. Can you please state your age?

27. Can you tell me the highest level of education you have completed?

28. Can you please identify your racial or ethnic background?

29. Is there anything else you would like to say about the merger that you have not said already? 


\section{Interview Questions}

Paralegals

1. What is your job title at A-Z Law?

2. Please describe your major job duties.

3. Which company were you employed by before the merger?

4. Have your duties changed since the merger? (If yes, in what ways?)

5. Can you please describe to me in detail your work life before the merger?

6. Can you please describe to me in detail your work life after the merger?

7. How did you hear about the merger?

8. What did your former employer, that is your employer before the merger, do to address the merger?

9. What were your initial feelings about the merger between ABC Law, XYZ Law, and EquiLaw?

10. What are your feelings about the merger now?

11. What was your feeling about working with the employees of the other firms?

12. What specifically did the new firm do to introduce employees from all three firms?

13. What is your impression of A-Z Law's current expectations of their employees?

14. How do you feel about the standards for billable hours? What were the standards before the merger?

15. How do the firm's demands impact your life outside the firm? 
16. How would you define success on a daily basis?

17. How do you feel about the administrative staff at A-Z Law?

18. How do you feel about the attorneys at A-Z Law?

19. How do you regard your former employer compared to the new firm?

20. What concerns do you have about the new firm's overall operation?

21. What would you regard as being the positive aspects of the merger?

22. What would you regard as being the negative aspects of the merger?

23. Can you please state your gender?

24. Can you please state your age?

25. Can you tell me the highest level of education you have completed?

26. Can you please identify your racial or ethnic background?

27. Is there anything else you would like to say about the merger that you have not said already? 


\section{Interview Questions}

Secretaries

1. What is your job title at A-Z Law?

2. Please describe your major job duties.

3. Which company were you employed by before the merger?

4. Have your duties changed since the merger? (If yes, in what ways?)

5. Can you please describe to me in detail your work life before the merger?

6. Can you please describe to me in detail your work life after the merger?

7. How did you hear about the merger?

8. What did your former employer, that is your employer before the merger, do to address the merger?

9. What were your initial feelings about the merger between ABC Law, XYZ Law, and EquiLaw?

10. What are your feelings about the merger now?

11. What was your feeling about working with the employees of the other firms?

12. What specifically did the new firm do to introduce employees from all three firms?

13. What is your impression of A-Z Law's expectations of their employees?

14. How would you describe your typical workload?

15. What happens on a day where the completion of a given project will last past regular work hours?

16. How do the firm's demands impact your life outside the firm? 
17. How would you define success on a daily basis?

18. How do you feel about the administrative staff at A-Z Law?

19. How do you feel about the paralegals at A-Z Law?

20. How do you feel about the attorneys at A-Z Law?

21. How do you regard your former employer compared to the new firm?

22. What concerns do you have about the new firm's overall operation?

23. What would you regard as being the positive aspects of the merger?

24. What would you regard as being the negative aspects of the merger?

25. Can you please state your gender?

26. Can you please state your age?

27. Can you tell me the highest level of education you have completed?

28. Can you please identify your racial or ethnic background?

29. Is there anything else you would like to say about the merger that you have not said already? 


\section{Interview Questions}

Other Employees

1. What is your job title at A-Z Law

2. Please describe your major job duties.

3. Which company were you employed by before the merger?

4. Have your duties changed since the merger? (If yes, in what ways?)

5. Can you please describe to me in detail your work life before the merger?

6. Can you please describe to me in detail your work life after the merger?

7. How did you hear about the merger?

8. What did your former employer, that is your employer before the merger, do to address the merger?

9. What were your initial feelings about the merger between ABC Law, XYZ Law, and EquiLaw?

10. What are your feelings about the merger now?

11. What was your feeling about working with the employees of the other firms?

12. What specifically did the new firm do to introduce employees from all three firms?

13. What is your impression of A-Z Law's expectations of their employees?

14. How would you describe your typical workload?

15. What happens on a day where the completion of a given project will last past regular work hours?

16. How do the firm's demands impact your life outside the firm? 
17. How would you define success on a daily basis?

18. How do you feel about the administrative staff at A-Z Law?

19. How do you feel about the paralegals at A-Z Law?

20. How do you feel about the attorneys at A-Z Law?

21. How do you regard your former employer compared to the new firm?

22. What concerns do you have about the new firm's overall operation?

23. What would you regard as being the positive aspects of the merger?

24. What would you regard as being the negative aspects of the merger?

25. Can you please state your gender?

26. Can you please state your age?

27. Can you tell me the highest level of education you have completed?

28. Can you please identify your racial or ethnic background?

29. Is there anything else you would like to say about the merger that you have not said already? 


\section{APPENDIX B}

\section{*Stratified Random Sampling of the Law Firm Population}

Position

Total Number

Target Number

\begin{tabular}{|c|c|c|}
\hline Partners & 22 & 5 \\
\hline Associates & 9 & 2 \\
\hline Paralegals & 7 & 2 \\
\hline Secretary & 18 & 5 \\
\hline $\begin{array}{l}\text { Other (includes } \\
\text { Service Center, } \\
\text { Marketing, } \\
\text { Accounting, } \\
\text { Information Systems, } \\
\text { and Runners) }\end{array}$ & 12 & 3 \\
\hline
\end{tabular}

Total

68

17

* The sampling strategy was intended to gather a $25 \%$ sample of all employees who experienced the merger. Within each stratified segment, the names were alphabetically arranged. Every fourth name was selected until the total of the $25 \%$ sampling requirement is fulfilled. In the case of refusal, the next name appearing alphabetically was chosen. 


\section{APPENDIX C \\ Corporate Change and Integration as a Result of A Merger: An Analysis of Organizational Culture within a Large Full-Service Law Firm}

\section{Subject Informed Consent}

\section{Introduction and Background Information}

You are invited to participate in a research study. The study is being conducted by Ilker Onen. The study is under the supervision of Dr. Cynthia Negrey, PhD and sponsored by the University of Louisville Department of Sociology.

\section{Purpose}

The purpose of this research study is to investigate the impressions of employees experiencing a merger between multiple organizations. Furthermore, the analysis of each firm's organizational culture is central to this goal. The entire study will occur over a 3-4 month span.

\section{Procedures}

In this study, you will be asked to answer various questions through an intervicw. The interview is being used to acquire a fuller understanding of each employee's impression of the merger. You may refuse to answer any question(s) that may make you feel uncomfortable. The interview will last approximately one hour at a site away from the office. However, if time constraints or other developments occur during the course of the interview, every effort to accommodate the participant will be made.

\section{Potential Risks}

Steps are being taken to protect the confidentiality and anonymity of participants and the firm alike. There are no foreseeable risks to your participation in this study. 


\section{Benefits}

The possible benefit of this study includes a greater understanding of organizational culture during a merger. However, the information collected may not benefit you directly.

\section{Confidentiality}

Although absolute confidentiality cannot be guaranteed, confidentiality will be protected to the extent permitted by law. The Sociology Department, Institutional Review Board (IRB) and Human Subjects Protection Program Office (HSPPO) may inspect your research records. In addition, the firm reserves the right to review a copy of the thesis before final submission to the University of Louisville. However, all possible measures of assuring participant confidentiality and anonymity are being taken. Specific identifying characteristics of neither the firm nor the participants will be disclosed. Interviews will be identified by number and not by name. Furthermore, legacy firm names will be replaced by fictitious terms. Should the data collected in this research study be published, your identity will not be revealed.

\section{Voluntary Participation}

Your participation in this study is voluntary. You may refuse to participate or withdraw you consent at any time.

\section{Research Subject's Rights and Contact Persons}

You acknowledge that all your present questions have been answered in language that you can understand and all future questions will be treated in the same manner. If you have any questions about the study, please contact Ilker Onen at (859) 2550842 or Dr. Cynthia Negrey, my thesis supervisor, at (502) 852-8023.

If you have any questions about your rights as a research subject, you may call the HSPPO office (502) 852-5188. You will be given the opportunity to discuss any questions about your rights as a research subject, in confidence, with a member of the IRB. The IRB is an independent committee composed of members of the University community, staff of the institutions, as well as lay members of the community not connected with these institutions. The IRB has reviewed this study. 


\section{Consent}

You have discussed the above information and hereby consent to voluntarily participate in this study. You have been given a signed copy of the consent form.

Signature of Subject

Signature of Investigator
Date Signed

Date Signed

Corporate Change and Integration as a Result of $\mathbf{A}$ Merger: An Analysis of Organizational Culture within a I arge 


\section{APPENDIX D}

\section{Invitation Letter}

Ilker H. Onen

157 Constitution Street

Lexington, Kentucky 40507

(859) 255-0842

ievilgenius@yahoo.com

(Month/Day/Year)

\section{Dear (name)}

You have been invited to participate in a research study. The purpose of this study is to research the effects of a merger on the employees of an organization. The principle form of the research design will be an interview lasting around an hour. This research is under the auspices of the University of Louisville for the completion of my Master's Thesis.

A-Z Law was made aware of my intent to contact you to participate in this research. The research has neither been initiated nor sponsored by A-Z Law The research is strictly independent of the firm. However, for purposes of protecting the firm's identity, A-Z Law retains the right to review a draft of the thesis prior to final submission. This draft along with all other aspects of the research will be assured of participant anonymity. Based on the research design, the disclosure of specific identifying characteristics of both the firm and individuals is strictly prohibited. My intention is to study the impressions of employees after a merger has taken place. Participation in this study is strictly voluntary. If you should choose to participate, confidentiality in regards to the content of the interview and your individual anonymity are assured to the fullest extent.

As a researcher, I understand your dedication to your family and work life. I will pursue these interviews in accordance to your availability. In addition, we will negotiate in selecting a discreet location for the interview. For purposes of efficiency, and if you agree, I will record the entire interview on audio tape. Each 
tape will be identified by number and not by name. I will retain the data in my possession for interpretation and subsequent reporting. Once again, all the materials produced during the course of the research will be held with utmost respect for anonymity and confidentiality.

If you choose to participate in the aforementioned study, please respond to this letter at your earliest convenience. You may choose to respond by e-mail, telephone, or self-addressed envelope provided. However, you are not obligated to volunteer. I will attempt to make contact discreetly only after your voluntary participation is granted. For purposes of maintaining the integrity of A-Z Law, all contact regarding the research is to be made outside the firm's premises and beyond working hours. I greatly appreciate your time and consideration in this matter.

Sincerely,

Ilker Onen 


\section{CURRICULUM VITAE}

NAME: $\quad$ Ilker Huseyin Onen

ADDRESS: 157 Constitution Street

Lexington, Kentucky 40507

EDUCATION

\& TRAINING: $\quad$ B.A., Business Administration

Tiffin University

1991-1995 